\title{
Caracterización del empleo doméstico en la Argentina ${ }^{\dagger}$
}

\author{
Juan Cruz Llambías*
}

\section{Resumen}

La rotación de la pirámide poblacional y el incremento de la participación laboral femenina resultan en una creciente importancia del empleo doméstico en Argentina. Analizando la oferta y la demanda de estos servicios, este trabajo busca brindar información que permita un mejor diseño de políticas públicas en busca de mejorar la situación de quienes intervienen en este mercado. Utilizando bases del INDEC (EPH y CGI), se estudia la relación de los empleados domésticos con la informalidad, la pobreza, la inmigración y el género femenino. Se realizan estimaciones de la incidencia de la pobreza sobre los empleados domésticos junto con un análisis del vínculo entre sus remuneraciones y el salario mínimo. Luego, utilizando la base de ENES (PISAC) se caracteriza a los demandantes de estos servicios desde cuatro enfoques: Ingresos, Geografía, Educación y Género. Se observa que el estatus y la cuestión de genero podrían jugar un papel importante en el lado de la demanda. Asimismo, los resultados sugieren que el salario mínimo podría estar siendo un punto de referencia al momento de pactar contratos en el mercado formal y en el informal. Finalmente, se exponen políticas públicas realizadas en otros países en busca de mejorar el bienestar de los implicados.

Palabras clave: demanda de empleo doméstico, oferta empleo doméstico, inmigración, empleo informal.

\begin{abstract}
Aging populations and the rise in women's economic participation led to an increase in domestic employment's relevance. Analyzing not only supply but also demand of these services in Argentina, this work seeks to provide information to help the future design of public policies pursuing to improve the well-being of those involved in this market. Using INDEC databases (EPH and CGI), this paper studies the relationship of domestic employees with informality, poverty, immigration and gender. The study analyzes poverty between the first semesters of 2017 and 2019. These results are used to simulate poverty scenarios given changes in domestic employees' income. An analysis of the relation between salaries and the minimum wage is also provided. Then, using the ENES database (PISAC), demand is described by four features: Income, Geography, Education and Gender. The analysis suggests that both status and gender could play an important role in the demand for these services. Moreover, the study suggests minimum wage could be a benchmark for both formal and informal labor contracts. Finally, the study provides a brief description of different public policies aiming to improve the wellbeing of those involved in this market.
\end{abstract}

Keywords: demand of housekeeping services, supply of housekeeping services, immigration, informal jobs.

JEL: J21, J23, J46, J61

DOI: https://doi.org/10.46553/ensayos.3.3.2021.p107-155

Fecha de recepción: 14/06/2020; Fecha de aceptación: 15/12/2020

\footnotetext{
${ }^{+}$Este trabajo es parte de mi tesis de licenciatura en la Universidad Católica Argentina (UCA). Agradezco especialmente a Pedro Martínez Bruera por sus sugerencias durante la elaboración de este trabajo, así como también los comentarios del editor y los dos referees anónimos.

* Universidad Torcuato Di Tella. Email: juancruzllambias@gmail.com
} 


\section{Introducción}

El empleo doméstico es un sector de creciente importancia en la estructura económica, sobre todo en América Latina. Según la Organización Internacional del Trabajo (OIT), entre 1995 y 2010 el número de trabajadores en este rubro en la región casi se duplicó, pasando de 10 a 20 millones aproximadamente (OIT, 2013) ${ }^{1}$. Las razones de esta tendencia podrían estar explicadas por la creciente necesidad de estos servicios ante el envejecimiento poblacional y la incorporación de la mujer al mercado laboral. El primer factor se ve agravado por la disminución en los hogares de estructuras multigeneracionales. Esto deja a los mayores en soledad, generando una mayor necesidad de estos servicios para realizar tareas de cuidado y limpieza. La mayor participación femenina en el mercado de trabajo afecta de una manera muy particular a este sector. Este fenómeno lleva a la necesidad de buscar alternativas para lidiar con las labores hogareñas ante una menor disponibilidad de tiempo por parte de la mujer. A su vez, es uno de los principales trabajos a los cuales las mujeres suelen recurrir en nuestra región. De hecho, la OIT estima que representa el $26,6 \%$ del trabajo remunerado femenino en América Latina (OIT, 2013).

Muchos países y en particular aquellos en donde se está invirtiendo la pirámide poblacional, comenzaron en los últimos años a destinar más recursos para investigar este mercado y realizar políticas económicas que permitan mejorar el bienestar de la población. Es decir, con el objetivo de mejorar la situación de los trabajadores del empleo doméstico y también de los que necesitan de sus servicios.

En este trabajo se busca realizar un análisis descriptivo de este mercado en la Argentina. A diferencia de gran parte de la literatura relacionada, el enfoque está puesto en estudiar tanto a oferentes como demandantes de empleo doméstico. El objetivo es otorgar herramientas a aquellos que investiguen el tema en un futuro para que se pueda comprender con mayor precisión el funcionamiento de las relaciones laborales que lo comprenden. Esto permitiría no sólo poner en agenda la necesidad de tener en cuenta a este sector y las problemáticas que enfrenta, sino que facilitaría un mejor diseño de políticas públicas dirigidas al mismo.

Al estudiar las características de la oferta de empleo doméstico, surgen los siguientes resultados. Se encuentra que se trata de un rubro con una informalidad del $72 \%$, siendo aquel con mayor tasa de informalidad en la economía argentina. Los resultados también indican que el salario mínimo podría estar funcionando como un punto de referencia para los contratos de trabajo formales e informales. Estos trabajos son ocupados por el género femenino prácticamente en su totalidad y se caracterizan por una presencia de inmigrantes bastante mayor que la media de la economía, especialmente si se considera sólo la Ciudad Autónoma de Buenos Aires, donde se alcanza una proporción del 37\%. Asimismo, se constata que es uno de los sectores peor remunerados en la economía. Esto conlleva a una incidencia en la pobreza marcadamente mayor que la correspondiente a la sociedad en su conjunto. Al realizar simulaciones de incrementos

\footnotetext{
1 La OIT indica que estos números subyacen de estadísticas oficiales de los gobiernos nacionales. Probablemente el monto real sea mayor por varias razones (OIT, 2016).
} 
en los salarios y de transferencias directas, se encuentra que políticas que busquen mejorar el nivel de ingresos de estos trabajadores mejoran considerablemente su situación y tienen un impacto no despreciable en la tasa de pobreza a nivel nacional.

Luego, el desarrollo vinculado a la demanda está enmarcado en los siguientes aspectos: nivel de ingresos, ubicación geográfica, educación y perspectiva de género. Se encuentra que el primer enfoque probablemente sea el de mayor relevancia ya que el resto estarían fuertemente vinculados a él. La excepción a esto la constituye el enfoque de género que revela una brecha en la que los hogares donde el principal proveedor de ingresos es mujer tienden a demandar más empleo doméstico que aquellos donde es el hombre. Dicha diferencia se acrecienta en los deciles más bajos de la distribución. Por otro lado, en el estudio por regiones se encuentra que también existen otros factores no relacionados al nivel de ingreso que afectan la cantidad demandada. Se encuentra también que la autopercepción de la ubicación en la escala socioeconómica juega un papel de igual o incluso mayor importancia que el nivel de ingresos, es decir, la ubicación efectiva.

Lo que resto de este trabajo se estructura de la siguiente manera: Las secciones 2 y 3 desarrollan brevemente el marco legal en Argentina y la bibliografía relacionada, respectivamente. A continuación, se describe la metodología utilizada. Luego, la sección 5 expone los resultados de este trabajo. La misma se divide en dos subsecciones correspondientes a la oferta y la demanda de empleo doméstico. En el siguiente apartado se desarrollan las implicancias de lo encontrado en términos de políticas públicas. Finalmente, se desarrollan las conclusiones en la sección 7.

\section{Aspectos jurídicos}

Previo a la sanción de la Ley $26.844^{2}$ en el 2013 , los trabajadores del servicio doméstico no contaban con una legislación laboral integral que proteja sus derechos. Esto se debe a que la Ley de Contrato de Trabajo los excluye explícitamente de su alcance en el artículo 2 de la misma. Por lo tanto, dichas relaciones laborales quedaban sujetas a lo establecido en el Decreto Ley 365 de 1956, el cual establecía un régimen mucho más simplificado que no otorgaba la protección y los beneficios que gozaban la mayoría de los trabajadores en nuestro país. A su vez, este excluía a una parte considerable de los empleados domésticos ya que no contemplaba a aquellos que presten sus servicios por un tiempo inferior a un mes, que trabajen menos de 4 horas por día o lo hagan por menos de cuatro días a la semana para el mismo empleador. Esto implica la exclusión de una parte de los empleados domésticos ya que el $21 \%$ trabaja para más de un empleador (EPH-4Q 2018). Esto implica que, en muchos de esos casos, pueden no llegar a cumplir el requerimiento de 4 horas diarias o al menos 4 días a la semana para un mismo empleador. Cabe aclarar que esto último también podría darse en aquellos que trabajen en un solo hogar.

\footnotetext{
${ }^{2}$ El Decreto 467/2014 la reglamenta.
} 
El Régimen Especial de Contrato de Trabajo para el Personal de Casas Particulares que rige desde el 2013, hace un notable cambio en este aspecto, ya que en el Artículo 1 de la misma expresa claramente que incluye a los trabajadores del servicio doméstico "cualquiera fuere la cantidad de horas diarias o de jornadas semanales en que sean ocupados para tales labores". Esto último es fundamental, ya que permite la no exclusión de una parte importante del trabajo brindado por este rubro.

La nueva ley, a su vez, contempla otros aspectos que ayudan a prevenir la denigración del empleo doméstico y promueven, desde las limitaciones del ámbito jurídico, la progresiva formalización de este sector, aunque sea indirectamente. Esto incluye protección del trabajo de la mujer en el embarazo, una jornada laboral menos extensa, un recargo por horas extra e indemnización por despido sin causa, entre otras cosas ${ }^{3}$. En esta línea, establece un período de prueba, cuya extensión dependerá si el personal fue contratado con o sin retiro, dentro del cual las dos partes pueden extinguir el contrato sin el derecho a recibir indemnización alguna. Esto permite reducir los costos de contratación, lo que brinda más dinamismo a la demanda de trabajo formal.

Dicha ley impone la necesidad de que la Comisión Nacional de Trabajo en Casas Particulares (CNTCP) fije un salario mínimo, entre otras funciones. El decreto 326/1956 daba al Poder Ejecutivo la obligación de fijarlo distinguiendo por zonas geográficas teniendo en consideración las distintas condiciones de vida en cada una de ellas y las modalidades de trabajo. Se sigue utilizando un criterio de ese estilo ya que el mínimo establecido para las zonas consideradas en condiciones desfavorables es mayor al resto.

Sin embargo, como afirma Birgin (2009), el acceso a la justicia no sólo debería ser tenido en cuenta desde la posibilidad de proteger derechos y resolver conflictos, sino en un sentido más amplio que incluya la igualdad de oportunidades. Es decir, no sólo es importante lo que diga la normativa para regular estas relaciones de trabajo sino otros aspectos que permitan a los ciudadanos reclamar lo que les corresponde. Dentro de ellos puede incluirse el conocimiento de la Ley y tener los medios necesarios para uno poder defender y reclamar sus derechos.

Podría ser clave la posibilidad de tener un sustento económico o la facilitación de asuntos "operativos", como el traslado a los juzgados, por ejemplo, ya que para quienes viven en situación de pobreza, dejar de trabajar para ir al juzgado y efectuar los gastos necesarios para los traslados y trámites constituye un costo significativo. En este sentido, la ley explicada muestra un avance haciendo gratuitas las cuestiones administrativas del régimen procesal en la Capital Federal para cualquier empleado 4 . A su vez, el bajo nivel educativo de los empleados domésticos constituye un grave problema 5 , ya que la falta de conocimiento de los derechos que a uno le corresponden también juega un papel importante. Por ello, darles a conocer cuáles son y cómo

\footnotetext{
3 También incluye la obligación de contratar un seguro de riesgos de trabajo, inexistente en la normativa previa.

${ }^{4}$ Se creó el Tribunal de Trabajo para el Personal de Casas Particulares que funciona como el órgano de resolución de conflictos en el empleo doméstico para la Ciudad de Buenos Aires.

5 Según la información obtenida de la EPH (4Q-2018), un $60 \%$ no llega a finalizar el nivel secundario y sólo un $3 \%$ tiene un terciario o universitario completo.
} 
ejercerlos es fundamental a la hora de buscar una progresiva formalización de este sector y lograr mayor equidad en la sociedad.

\section{Revisión bibliográfica}

En la literatura se observa un consenso general en el alto grado de precariedad del trabajo doméstico. Uno de los determinantes de ello podría ser la necesidad de recurrir al mismo por parte de los más pobres y marginados. En esta línea, el crecimiento de la fragmentación social como producto de la segregación residencial en los aglomerados urbanos ha llevado a agudizar la vulnerabilidad socioeconómica de los sectores más desfavorecidos. El trabajo de Groisman \& Suárez (2010) refleja evidencia de que la partición del espacio en las ciudades entre clases socioeconómicas provoca en los marginados una disminución en la probabilidad de acceso a un empleo de calidad y una penalidad en las retribuciones laborales ${ }^{6}$. Podría pensarse que este fenómeno se debe en parte a un rápido desarrollo no planificado de los grandes centros urbanos en nuestro país. En particular, el crecimiento descontrolado de la urbanización en el conurbano bonaerense está dado en parte por la persistencia de flujos de entrada de migrantes provenientes de la región, fundamentalmente de Bolivia y Paraguay (Maurizio, 2007). Esto podría ser una explicación de la considerable presencia de inmigrantes, sobre todo de países vecinos, en este sector.

El trabajo de Ceriani et al. (2009) destaca la relación entre las corrientes migratorias femeninas y el empleo doméstico en la Argentina. Se encuentra, con información del Censo del 2001, que los empleados domésticos inmigrantes en el país provienen principalmente de Perú, Chile y Paraguay. Con los datos presentados en su trabajo puede calcularse sencillamente que los extranjeros representaban un $11,6 \%$ de los trabajadores de este sector en Argentina. Cabe destacar que dicha relación sube al $45,6 \%$ restringiendo el análisis a la Ciudad de Buenos Aires. Por otro lado, los autores analizan el marco regulatorio vigente y critican la grave discriminación en cuanto a derechos laborales en relación con otros regímenes de contrato de trabajo. Esto último, según ellos, es una de las causas de la alta informalidad laboral en el rubro?.

En un estudio del sistema productivo argentino, Schteingart (2017) encuentra que el empleo doméstico es el sector de la economía con menor tasa de formalidad ${ }^{8}$ y mayor incidencia en la pobreza. Respecto a lo último, su estimación correspondiente al segundo trimestre del 2016 encuentra que ante un 32,2\% de personas bajo la línea de pobreza esa cifra se incrementa al $53,8 \%$ en los casos donde el jefe de hogar es empleado doméstico. Lo mismo constituye una diferencia sustancial y refleja la vulnerabilidad en que se encuentran los trabajadores de este sector.

\footnotetext{
${ }^{6}$ De hecho, verifican una mayor proporción de ocupados en el servicio doméstico en hogares segregados.

${ }^{7}$ Es menester aclarar que dicho trabajo fue realizado previo a la reforma del 2013 en que se creó el Régimen Especial de Contrato de Trabajo para el Personal de Casas Particulares.

${ }^{8}$ Su estimación es de un 23\% para el año 2013.
} 
Por otro lado, Bertranou \& Casanova (2013) encuentran en el empleo doméstico la mayor tasa de informalidad en la economía argentina para el 2003 y 2012. Adicionalmente, documentan una disminución considerable en la misma entre ambas estimaciones y realizan un muy breve análisis de algunas de las características estructurales de este mercado. Dada la constante mención a la informalidad del sector en la bibliografía, un documento que toma gran relevancia es el presentado por la OIT en 2016 (Formalizing domestic work). En él se propone un esquema de acciones para la formalización del mercado de empleo doméstico teniendo en cuenta la evidencia empírica de medidas tomadas por países en varias partes del mundo. Para ello se establecen tres pasos: extender el alcance de la ley, desincentivar la informalidad e incentivar la formalidad. En particular, se destacan en el marco legal las reformas de España en 2011 y Argentina en 2013. En cuanto al esquema de incentivos que hacen a uno más propenso a aceptar un contrato formal y a no desear uno informal, sobresalen los casos de Bélgica, Francia, Irlanda y Sudáfrica. Más adelante se brindarán más detalles de estos.

Las estadísticas de la OIT para el año 2010 (OIT, 2013), reflejan que América Latina es la región donde se da la mayor participación del empleo doméstico en el total $(7,6 \%)$, ubicándose Medio Oriente en segundo lugar (5,6\%). En los países del sur de África, donde tal vez la pobreza no alcanza dígitos muy altos, pero si tienen niveles de desigualdad preocupantes, las cifras son mayores y en algunos casos superan el $8 \%$. Una interesante incógnita por resolver es saber por qué en América Latina el empleo doméstico tiene un mayor peso que en el resto del mundo. Teniendo en cuenta un contexto general, las condiciones precarias de asentamiento en muchas ciudades de la región, la pobreza y las altas tasas de informalidad podrían tener una gran injerencia en ese hecho. Otro aspecto importante podría ser el aparente vínculo entre altos índices de desigualdad y una mayor presencia de este sector en la economía. Podría pensarse que el diferencial de ingresos entre los más ricos y los más pobres incrementa tanto la oferta como la demanda de estos servicios (Órdenes Carvajal, 2016).

La gran participación femenina en el sector pareciera ser un hecho en todo el mundo. La OIT (2013) estima una proporción de mujeres mayor al $80 \%$ a nivel mundial y del $93 \%$ para América Latina. A pesar de que se ha escrito poco acerca de cómo influye la perspectiva de género en la demanda de estos servicios, existen trabajos como el de Stancanelli \& Stratton (2014) que tratan de explicar aspectos relacionados. En particular, ellos estudian la evolución de la demanda de empleo doméstico ante cambios en el costo y los sueldos de la mujer y el hombre en parejas heterosexuales. Encuentran que un mayor costo de oportunidad en el tiempo dedicado a trabajo no remunerado se traduce en un incremento en la probabilidad de contar con servicio doméstico. Asimismo, cambios en la valoración del tiempo de la mujer (su salario) tienen un impacto mayor. Para comprender por qué podría darse este resultado, el trabajo de Domínguez Amorós et al. (2018) resulta de utilidad. En él se busca comprender la distribución de horas por día destinadas al "trabajo doméstico y de cuidados" no remunerado en el hogar por parte de las dos personas principales ${ }^{9}$. El análisis se restringe a parejas compuestas por

\footnotetext{
${ }^{9}$ A los efectos de la sección "la demanda de empleo doméstico" consiste en el Primer Sostén del Hogar y su conyugue.
} 
hombre y mujer en las que ambos están ocupados. Las autoras encuentran que, del total de horas diarias dedicadas a dichas labores por parte de ellas en la Argentina, la mujer realiza el $76 \%$ a pesar de que se hace cargo del $42 \%$ del trabajo remunerado perpetuado por ambos. Es decir, una inserción laboral cercana a equitativa en cantidad de horas de trabajo no conlleva a una asignación equivalente en las tareas del hogar. Dado que la mujer es la que se hace cargo de la mayor parte del trabajo no remunerado en el hogar, toma sentido que un aumento en el salario de ella sea más relevante en la probabilidad de acceder al empleo doméstico que cambios en el sueldo masculino.

Gran parte de los trabajos de investigación orientados al empleo doméstico estudian sólo algunos de los aspectos que lo caracterizan. En general, suelen enfocarse exclusivamente en lo relacionado a la informalidad, la inmigración o el marco regulatorio. Sin embargo, ciertos estudios como los realizados en Tailandia (OIT, 2010), Uruguay (Batthyany, 2012; Ministerio de Trabajo y Seguridad Social, 2015; Ministerio de Trabajo y Seguridad Social, 2019) y Chile (Órdenes Carvajal, 2016), analizan la oferta de servicio doméstico desde varios puntos de vista.

En el caso uruguayo, se estudia la evolución de las características de este tipo de empleo como resultado de una serie de políticas públicas orientadas al sector realizadas desde el 2005. Se encuentra una proporción significativa del servicio doméstico sobre el empleo total y el femenino, siendo las mismas del 5,8\% y 12,8\% para el 2018 (Ministerio de Trabajo y Seguridad Social, 2019). Por otro lado, el trabajo es femenino casi en su totalidad y las labores de cuidado componen una porción minoritaria de estos trabajadores $(30 \%)^{10}$. De gran importancia, se estima una incidencia de la pobreza notablemente mayor para los hogares compuestos por empleadas domésticas (Batthyany, 2012; Ministerio de Trabajo y Seguridad Social, 2019). A pesar de que, con incrementos en el salario mínimo a estas prestaciones por encima del régimen general, el salario por hora de las empleadas domésticas tuvo un aumento en términos reales muy superior al resto, no se verifica una reducción en la pobreza considerablemente mayor a la media ${ }^{11}$. Sin embargo, producto de las políticas realizadas se evidencia una reducción en la informalidad y un aumento en las prestaciones jubilatorias notablemente mayores que el promedio de la economía (Ministerio de Trabajo y Seguridad Social, 2015; Ministerio de Trabajo y Seguridad Social, 2019). De hecho, el empleo doméstico deja de ser el más informal, ocupando este lugar la construcción. Del lado de la demanda, los hogares que acceden a estos servicios son alrededor del $9 \%$ del total y la modalidad con retiro alcanza el $97 \%$ de los casos.

Órdenes Carvajal (2016) encuentra que el empleo doméstico como proporción del empleo femenino total ha ido cayendo este siglo en Chile. Sin embargo, la cantidad de puestos de trabajo generados se mantuvo estable, con una leve caída en la informalidad. Asimismo, encuentra que el $97 \%$ de los trabajadores son de sexo femenino y que la modalidad con retiro fue creciendo en importancia desde 1990, alcanzando el $94 \%$ de los casos en el 2013. Por otro lado, evidencia una marcada disminución en la jornada

\footnotetext{
${ }^{10}$ A pesar de ello, se evidencia un crecimiento significativo de su participación en los últimos años.

11 Tanto en el caso uruguayo como el chileno, aunque los empleados domésticos siguen siendo uno de los sectores peor remunerados, su posición respecto a la media de la economía ha mejorado.
} 
laboral promedio de las empleadas domésticas en las últimas décadas. La autora obtiene que la proporción de trabajadoras dedicadas al empleo doméstico es mayor en los deciles más bajos de la distribución y que el porcentaje de ellas que es jefa de hogar ha experimentado un sostenido crecimiento desde 1996 alcanzando el 44\% en 2013. En consonancia con lo anterior, la incidencia de la pobreza en las empleadas domésticas es mayor que para el resto de las ocupaciones y esta brecha se incrementa al utilizar una metodología de pobreza multidimensional. Por último, el empleado doméstico promedio pasa un $48,5 \%$ de los meses de su vida laboral activa en ese rubro, un $20 \%$ dedicado al trabajo asalariado en otras labores, un $11 \%$ en el desempleo y un $22 \%$ a actividades fuera del mercado de trabajo.

Aunque estudian el tema desde una perspectiva diferente, los trabajos nombrados coinciden en la alta presencia femenina en el sector y el bajo nivel educativo de sus trabajadores. A su vez, destacan el aumento de la participación laboral femenina como causante de un progresivo incremento en la demanda de estos servicios. A pesar de su amplio tratamiento, difieren marcadamente con este escrito en la metodología utilizada $y$ el enfoque brindado.

El presente trabajo se diferencia de la literatura existente por su enfoque integral. Se busca una descripción completa de este mercado, por lo que no se estudia en profundidad un solo aspecto de este. A su vez, las investigaciones relacionadas a esta temática suelen dedicar sus esfuerzos exclusivamente a estudiar la oferta de empleo doméstico. A diferencia de ello, aquí se brinda un estudio que también abarca los determinantes de la demanda.

\section{Metodología}

La definición de empleo doméstico que se usará para este trabajo es la que nos brinda la Ley 26.844 (Régimen Especial de Contrato de Trabajo para el Personal de Casas Particulares). En su segundo artículo define lo siguiente: "Se considerará trabajo en casas particulares a toda prestación de servicios o ejecución de tareas de limpieza, de mantenimiento u otras actividades típicas del hogar. Se entenderá como tales también a la asistencia personal y acompañamiento prestados a los miembros de la familia o a quienes convivan en el mismo domicilio con el empleador, así como el cuidado no terapéutico de personas enfermas o con discapacidad." Por lo tanto, en este trabajo, se entiende como empleo doméstico a aquel referido a labores no calificadas de limpieza y cuidado en casas particulares.

\section{IV.1 Oferta de empleo doméstico}

Para esta sección se recurre a la Cuenta de Generación de Ingreso e Insumo de Mano de Obra (CGI) y la Encuesta Permanente de Hogares (EPH), ambas del INDEC.

Los resultados de la EPH son publicados trimestralmente. Para la misma se encuestan a 25 mil hogares distribuidos en 31 aglomerados urbanos alrededor del país. En cada caso, se hace una encuesta del hogar y una individual a cada una de las personas que forman 
parte de este. La misma provee información sobre una gran variedad de características de los encuestados. Entre ellas se encuentran aspectos habitacionales, laborales, económicos, migratorios, educativos y sobre la estructura familiar. Aprovechando esto, en este trabajo, se busca entender la relación de la oferta de empleo doméstico con la pobreza, la educación, el género y la inmigración en nuestro país.

La CGI se publica trimestralmente desde el 2016, con información obtenida de las siguientes fuentes: Censo Nacional de Población, Hogares y Viviendas 2010 y sus proyecciones poblacionales, Censo Nacional Económico 2004, EPH, ENGH 2004-2005, Encuesta Nacional a Grandes Empresas (ENGE), Sistema Integrado Previsional Argentino (SIPA) y otros registros de la administración pública. Esta base de datos brinda información sobre la estructura productiva Argentina. Para distintos sectores, permite obtener el valor agregado bruto y la cantidad de asalariados registrados y no registrados, entre otras cosas. En la misma, al hablar de empleo doméstico, se hace referencia a empleadas domésticas, cocineros, mayordomos, jardineros, choferes, niñeras y cuidado de ancianos en casas particulares. Ante la falta de fuentes de información más precisas, se considera que el grueso de este grupo de labores está compuesto por el sector objetivo y que, en cuanto a la producción e informalidad, el resto se comportan de manera similar al mismo. Por estas razones la información que otorgue esta variable proxy puede ser de utilidad.

Con dicha información se busca obtener características de la oferta de empleo doméstico relacionadas al nivel de ingresos y la informalidad. Para este análisis se elaboraron los índices explicados a continuación.

\section{IV.2 Índices}

Para la descripción de la oferta en este mercado, se elabora un índice de productividad por sector y otro de la posición en el nivel de ingresos con la información provista por la CGI. Siguiendo la metodología utilizada por Schteingart (2017), se toma como medida de productividad al valor agregado bruto por puesto de trabajo. Luego, el nivel de ingreso tomado como referencia es la media de la remuneración total a los asalariados de cada sector. La fórmula utilizada para ambos índices es la misma.

Siendo:

Productividadi: La productividad del sector i.

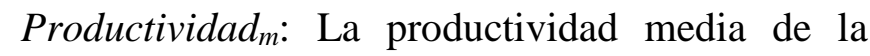

economía.

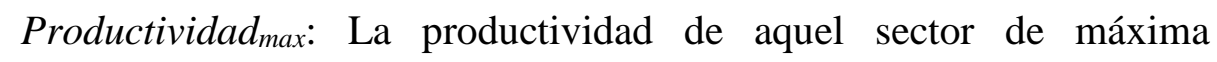
productividad.

Productividad $_{\text {min }}$ : La productividad de aquel sector con menor productividad. 
Si Productividad $_{i}>$ Productividad $_{m}$ : Índice de productividad

$=50+50 *\left(\frac{\operatorname{productividad}_{\mathrm{i}}-\text {-roductividad }_{\mathrm{m}}}{\text { productividad }_{\max }-\operatorname{productividad}_{\mathrm{m}}}\right)$

$\mathrm{Si} \quad$ Productividad $_{i}<$ Productividad $_{m}$ : Índice de

$\operatorname{productividad}_{\mathrm{i}}=\mathbf{5 0}+\mathbf{5 0} *\left(\frac{\operatorname{productividad}_{\mathrm{i}}-\operatorname{productividad}_{\mathrm{m}}}{\text { productividad }_{\mathrm{m}}-\operatorname{productividad}_{\min }}\right)$

Se divide a la muestra en dos partes. Los valores menores a 50 por un lado y los mayores por el otro. En cada tramo, el indicador refleja la posición relativa de un sector respecto a la media nacional y el rubro de mayor/menor productividad (mayor si supera al promedio y menor en caso contrario). Las productividades mínima, media y máxima obtienen los valores 0,50 y 100 respectivamente. Es decir, un valor de 25 no indica que la rama analizada tenga la mitad de la productividad media nacional, sino que se encuentra en el medio entre la misma y la correspondiente al sector menos productivo. Para mayor claridad se trata el siguiente ejemplo. Si la productividad del sector menos productivo fuera 10 , la de "comercio" 15 , la media nacional 20 , la de "pesca" 22,5 y la máxima fuera 25 para "enseñanza", el valor del índice sería respectivamente $0,25,50$, 75 y 100 . Entonces, el mismo refleja qué posición ocupa un sector entre la media y el extremo más cercano.

El índice de posición en el nivel de ingreso fue calculado de la misma manera (con ingreso en lugar de productividad). Para una mejor comprensión de los gráficos, los sectores "Comercio", "Servicios sociales y de salud" y "Otras actividades de servicios comunitarios, sociales y pensionales" fueron omitidos.

Para estudiar la informalidad se utiliza un indicador elaborado de la siguiente manera. Siendo AR y ANR los asalariados registrados y no registrados:

Tasa de informalidad $(T i)=\frac{A N R}{A N R+A R}$

Tasa de formalidad $=1-\mathrm{Ti}$

A su vez, se complementa el estudio de la informalidad con la EPH en la determinación del salario por hora promedio. Se calcula dividiendo el ingreso de la ocupación principal por la cantidad de horas dedicadas a la misma. Luego, se estima su valor para el mercado formal e informal controlando por quienes cuentan con descuento jubilatorio. Esto es de suma utilidad para la comparación entre el salario de mercado y el sueldo mínimo establecido legalmente.

Por último, la pobreza por ingresos fue estimada utilizando la metodología del INDEC, recurriendo a las mediciones de la Canasta Básica Total y la EPH. Para ello se trabaja con semestres móviles de la siguiente manera: 
- Semestre móvil 1 del año yyyy (SM1 - yyyy): primer y segundo trimestre.

- Semestre móvil 2 del año yyyy (SM2 - yyyy): segundo y tercer trimestre.

- Semestre móvil 3 del año yyyy (SM3 - yyyy): tercer y cuarto trimestre.

- Semestre móvil 4 del año yyyy (SM4 - yyyy): cuarto trimestre y el primero del año siguiente.

Se utiliza este enfoque para hacer un seguimiento de la evolución de la tasa de pobreza, tratando de evitar la estacionalidad producida por aquellos trimestres donde se registra el aguinaldo recibido por los hogares. Cabe notar que los semestres móviles 1 y 3 corresponden las mediciones del primer y segundo semestre que realiza el INDEC.

Para estimar la pobreza se trabaja arbitrariamente con la EPH a partir del 2017. El análisis podría extenderse hasta el segundo semestre móvil del 2016 eventualmente. Estos resultados no son comparables con los que se obtendrían de analizar períodos anteriores debido a los cambios metodológicos ocurridos en el 2016. De todas formas, el INDEC recomienda mirar con ciertas reservas las encuestas elaboradas entre el 2007 y $2015^{12}$.

\section{IV.3 Demanda de empleo doméstico}

Para esta parte del trabajo se obtiene información a partir de la Encuesta Nacional sobre la Estructura Social (ENES). La misma fue llevada a cabo por el Programa de Investigación sobre la Sociedad Argentina Contemporánea (PISAC) en un período entre el segundo semestre del 2014 y el primero del 2015. La ENES relevó un total de 8.625 hogares y 27.609 personas a lo largo del territorio urbano nacional. Su diseño permite obtener resultados regionales y acerca de algunos aglomerados importantes. Esta encuesta provee información precisa acerca de la estructura socioeconómica de los hogares. Si bien muchos de los datos son similares a los que otorga la EPH, se diferencia de ella en la especificidad. Por ejemplo, posibilita conocer en mayor profundidad características del hogar como la distribución de tareas hogareñas, el manejo de una computadora por parte de sus miembros o la autopercepción en la escala socioeconómica. A partir de ella se busca contribuir al análisis de este lado del mercado en las temáticas de género, ingresos, educación y ubicación geográfica.

Es importante explicar que la información que brinda esta base de datos no es tan precisa como uno quisiera para este análisis. En cuanto al personal correspondiente a tareas de limpieza y cuidado en el hogar, la encuesta no permite disgregar las labores calificadas de aquellas que no lo son. Por ello, es probable que se esté incluyendo información de personas que no cumplen con nuestra definición, en particular en cuanto al "servicio de cuidado de adulto mayor/discapacitado/persona enferma". A pesar de ello se considera que son una minoría en la información relevada por lo que el comportamiento de esas variables podría servir para explicar las características de los hogares demandantes de empleo doméstico.

\footnotetext{
12 "No se incluyen datos de trimestres anteriores dado que, conforme a la emergencia estadística, el INDEC ha dispuesto que las series publicadas con posterioridad al primer trimestre de 2007 y hasta el cuarto trimestre de 2015, deben ser consideradas con reservas." (INDEC, 2016, p. 1)
} 


\section{Resultados}

\section{V.1 Oferta de empleo doméstico}

\section{V.1.1 Informalidad}

La Figura 1 consiste en burbujas de distintos sectores productivos de la economía argentina. En el eje de ordenadas se mide la posición del nivel de ingreso medio de un sector con relación al resto. De esta manera, un valor del índice de posición en el nivel de ingreso de " 0 " o " 100 " indica que es el rubro de menor o de mayor nivel de ingreso medio, respectivamente. Un valor de " 50 " indica que la rama tiene el mismo ingreso medio que la media nacional. En el eje de abscisas se toman valores del índice de formalidad elaborado y el tamaño de las burbujas refleja la cantidad de puestos de trabajo que genera cada sector.

Figura 1: Informalidad y posición en el nivel de ingreso por sector.

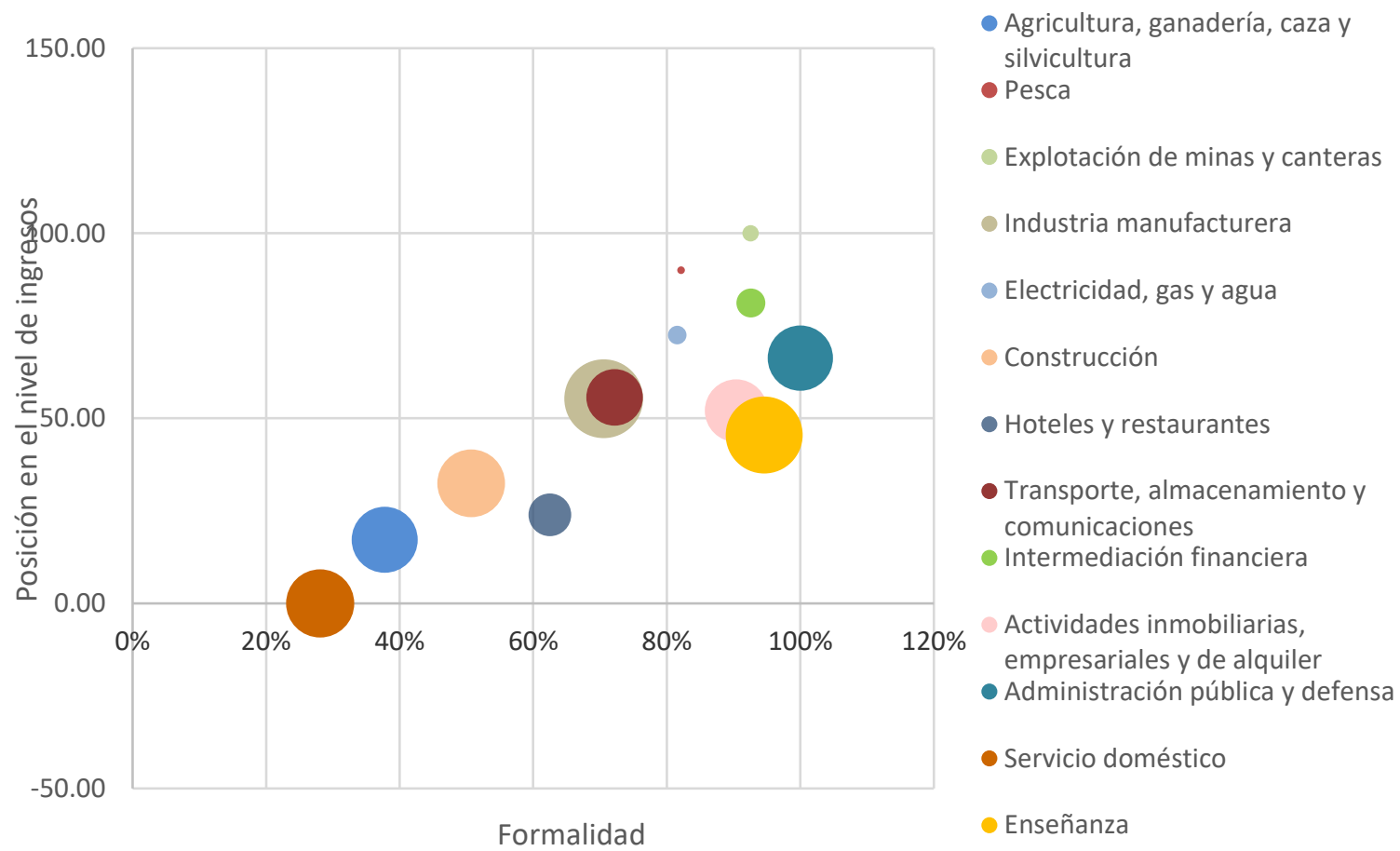

Fuente: elaboración propia en base a Cuenta de Generación del Ingreso e Insumo de Mano de Obra del INDEC.

Al observar la Figura 1 se encuentra una vinculación entre nivel de ingreso y formalidad. Se puede ver que sectores de alta formalidad (explotación de minas y canteras, por ejemplo) son aquellos de mayor nivel de ingreso. También aquellos que tienen un ingreso apenas debajo de la media de la economía (construcción) tienen un nivel de 
formalidad similar a la media nacional. Esto puede significar que, al aumentar el nivel de ingreso, los costos de formalizarse relativos a este disminuyen, mientras que los relacionados a mantenerse en la informalidad aumentan.

La burbuja inferior es el sector del servicio doméstico, lo que muestra que es el peor remunerado de toda la economía y aquel con la mayor informalidad. Mientras tanto, el tamaño de esta hace referencia a la cantidad de puestos de trabajo que produce. Por ello, al emplear una significativa cantidad de personas $(1,7$ millones de puestos de trabajo al último trimestre del 2018) y por las vulnerabilidades a las que están expuestas ${ }^{13}$, se trata de una rama de la economía que debería ser tenida en cuenta en la realización de políticas económicas que busquen mejorar el bienestar de la sociedad.

En particular, la estimación realizada arroja una informalidad de aproximadamente un $71 \%$ en el sector. Utilizando la EPH para el mismo período (4Q 2018), encontramos que el $74,42 \%$ de los trabajadores del empleo doméstico no acceden a una obra social por su trabajo y el $75,63 \%$ no cuentan con descuento jubilatorio. Siendo que estos dos aspectos son aquellos que se suelen utilizar para estimar la formalidad de un sector, estos resultados se encuentran en línea con lo estimado por la variable proxy utilizada en este trabajo. A su vez, están levemente debajo de lo obtenido para el 2013 por Schteingart (2017) en Argentina y la OIT (2016) en toda América Latina ${ }^{14}$.

En la Figura 2, se puede ver que la variación de la tasa de informalidad en el sector sigue la misma tendencia que la media nacional, sin embargo, es notoria la mayor volatilidad de la última. Como ya se evidenció en la Figura 1, el sector de empleo doméstico es el más informal de la economía. Por lo tanto, podría suceder que existan factores característicos de este rubro que afecten su informalidad y no se vean modificados considerablemente ante el crecimiento económico. Más aún, existen sectores que son altamente informales por razones específicas de los mismos, donde políticas sectoriales serían más efectivas que enfoques generales aplicados a toda la estructura productiva. En particular, el empleo doméstico se distingue dentro del mundo informal por ser llevado a cabo en un ambiente privado, por no estar contenido dentro de los marcos regulatorios convencionales en muchos países y porque es fácil de esconder dadas ciertas costumbres sociales y un contexto altamente personalizado (OIT, 2015). Luego, para lograr cambios significativos en la formalidad del rubro, son necesarias reformas que tengan en cuenta estos aspectos inherentes al empleo doméstico, más allá de los efectos del crecimiento económico.

\footnotetext{
13 Las que se desarrollan en este trabajo.

${ }^{14}$ El primero encuentra una tasa de formalidad del 23\% para el empleo doméstico en Argentina. La OIT estima una informalidad del 77,5\% para el sector en América Latina.
} 
Figura 2: Variación porcentual de la tasa de informalidad del empleo doméstico vs economía en su conjunto - variación respecto al trimestre anterior.

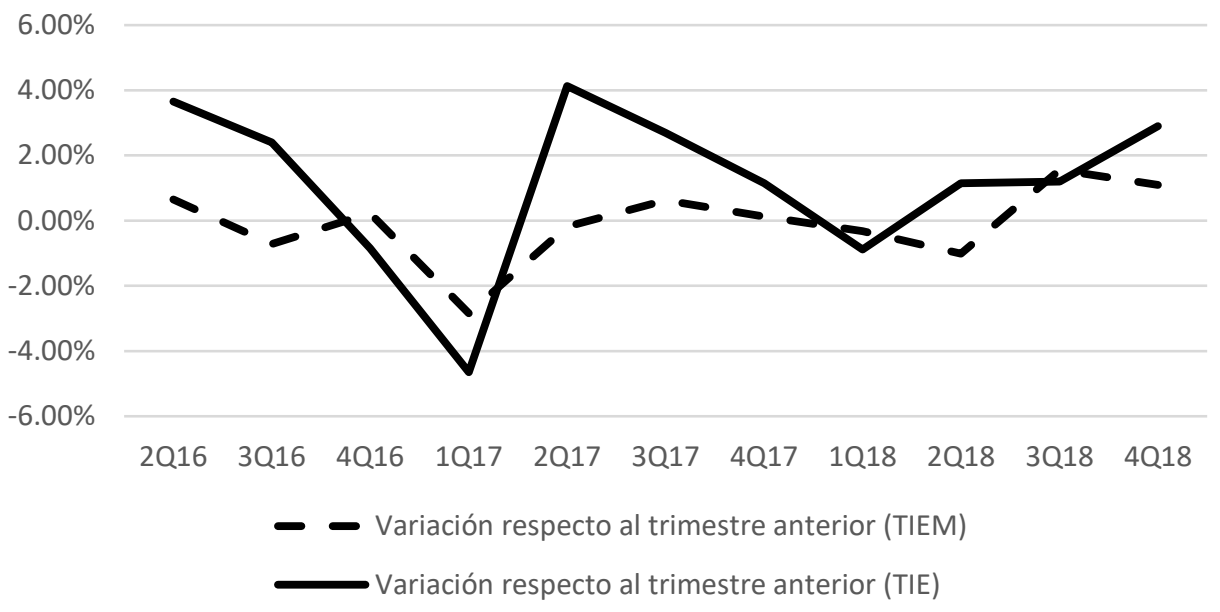

Nota: TIED: Tasa de informalidad del empleo doméstico. TIE: Tasa de informalidad de la economía. Fuente: Elaboración propia en base a Cuenta de Generación del Ingreso e Insumo de Mano de Obra del INDEC.

Por otro lado, en la Figura 3 se ve que la variación en la cantidad de puestos de trabajo en el sector analizado se explica principalmente por el cambio en los puestos de trabajo no registrados de dicho sector, es decir, en los empleados domésticos informales.

En este gráfico puede verse que la cantidad de puestos de trabajo registrados tiene una volatilidad marcadamente menor a lo largo del tiempo en relación con los informales. Por supuesto esto refleja una vulnerabilidad mayor para los últimos, quienes gozan de una baja estabilidad laboral. Asimismo, las variaciones en los puestos de trabajo totales se explican casi en su totalidad por cambios en la cantidad de trabajadores no registrados ${ }^{15}$.

Esto podría ocurrir por diversas razones. Primero, como refleja con claridad la Figura 4, este sector de la economía está principalmente "en negro", por lo que cambios en la parte no registrada, pesarán más en la variación total que cambios en la registrada. Además, en los pocos casos que el asalariado está registrado, los empleadores suelen tener más capacidad para sobrellevar los ciclos de la economía, pudiendo sostener la relación laboral. Más aún, los empleados suelen ser registrados una vez que el trabajo deja de ser temporal y pasa a ser permanente a los ojos del empleador, lo cual asegura una cierta estabilidad. También sabemos que, al tener un trabajador en situación de informalidad, los costos de despido y contratación son mucho menores. Por último, el gasto de los hogares en servicio doméstico representa el 9,8\% de los ingresos totales

${ }^{15}$ El gráfico 1 del apéndice podría ayudar a una mejor comprensión de este argumento. 
según la ENGHO 2004-2005 (Bertranou \& Casanova, 2013). Por lo tanto, se ve que constituye una porción considerable del presupuesto familiar, por lo que tendría sentido que se ajuste por ese lado ante dificultades económicas, sobre todo en casos de informalidad.

Figura 3: Variación trimestral en la cantidad de puestos de trabajo (en porcentaje)

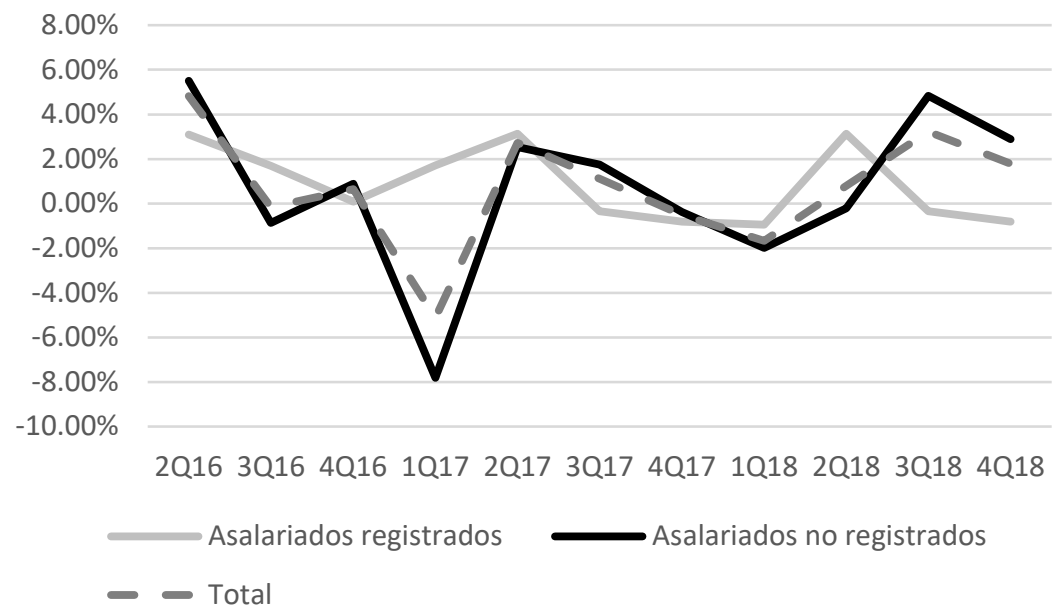

Fuente: elaboración propia en base a Cuenta de Generación del Ingreso e Insumo de Mano de Obra del INDEC.

La Comisión Nacional de Trabajo en Casas Particulares (CNTCP) es la encargada de fijar un salario mínimo para las labores comprendidas en el Régimen Especial de Contrato de Trabajo para el Personal de Casas Particulares. A partir de ello, es interesante estudiar cuál podría ser el impacto de esta medida en el rubro. En un mercado competitivo clásico, esto podría incentivar la informalidad del sector, ya que fijar salarios mínimos por encima del equilibrio de mercado podría generar dicho flagelo. Por supuesto, este caso no se daría si dicho salario mínimo $\left(w_{m}\right)$ estuviera por debajo del equilibrio de mercado $\left(w^{*}\right)$, caso en el cual, sería inútil poner un piso a estas prestaciones porque las contrataciones se efectuarían al salario de equilibrio. Entonces, imponer un salario mínimo por arriba del $w^{*}$, podría generar un exceso de oferta de empleados domésticos dispuestos a trabajar a ese nivel de $w_{m}$. Muchos aceptarían trabajar a un menor $w$, lo cual sería imposible en el marco legal dado, por lo que llevaría, posiblemente, a la creación de un mercado informal.

Por otro lado, estudios como el realizado por Groisman (2012) en Argentina demuestran que la imposición de un sueldo mínimo y sus consecuentes aumentos no generan migraciones del mercado laboral formal hacia el informal ni tampoco disminuyen la demanda de empleo total. Adicionalmente, Dinkelman \& Ranchhod (2010), analizando los efectos de la instauración de un piso al salario del empleo doméstico en Sudáfrica, no encontraron evidencia de una disminución en el empleo. Más aún, sus resultados sugieren que el sueldo por hora incrementó considerablemente producto de esta medida 
y que hubo un impacto positivo en la formalización del sector ${ }^{16}$. A pesar de ello, Velásquez Pinto (2017) concluye que los enfoques teóricos para analizar los efectos en el empleo de un aumento en el salario mínimo son diferentes y predicen efectos contrarios, por lo que la experiencia analizada en países desarrollados y en desarrollo indica que no puede anticiparse el impacto en el empleo de dicha medida.

Figura 4: Informalidad en el empleo doméstico (en porcentaje)

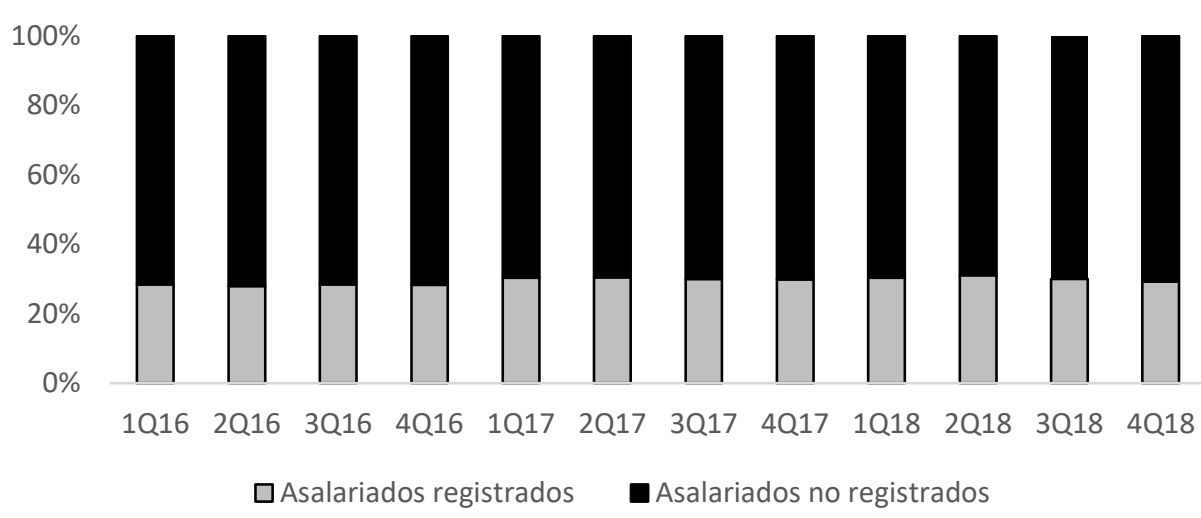

Fuente: elaboración propia en base a la Cuenta de Generación del Ingreso e Insumo de Mano de Obra del INDEC.

Un enfoque interesante es el adoptado por Khamis (2008). Ella encontró que la creación de un salario mínimo e incrementos en el mismo en Argentina produjeron un efecto positivo en las remuneraciones, con un mayor impacto en el mercado informal. En particular, concluye que el salario mínimo sirve de referencia para los contratos laborales en el mercado informal' ${ }^{17}$.

Figura 5: Variación acumulada del salario por hora (promedio trimestral) respecto del segundo trimestre de 2016.

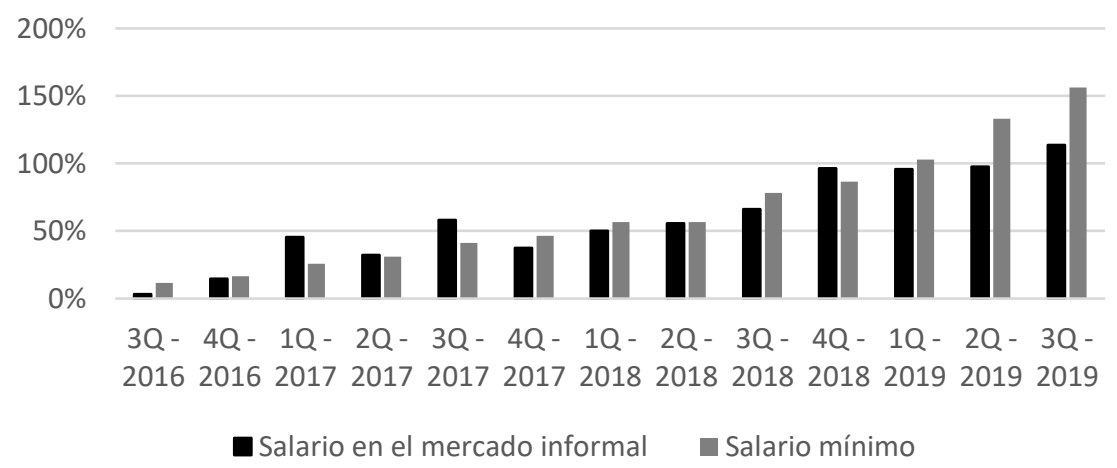

Fuente: elaboración propia a partir de la EPH del INDEC y la Comisión Nacional de Trabajo en Casas Particulares.

\footnotetext{
${ }^{16}$ Este progreso hacia la formalización se dio a pesar de no contar con medidas que aseguren el cumplimiento de la ley.

17 Este "efecto faro" también pareciera verificarse en Brasil entre los años 1995 y 2011 (OIT, 2013).
} 
Con la excepción del 2019 donde una fuerte recesión podría haber provocado un crecimiento menor de las remuneraciones en el mercado informal, estas parecen haber tenido como referencia los cambios en el salario mínimo establecido por la CNTCP.

Sin embargo, contrario a lo que predijo Khamis, esta vez fue el mercado formal el que siguió con mejor precisión los cambios en el salario mínimo, alcanzando una variación acumulada del salario por hora hasta el tercer trimestre del 2019 prácticamente igual.

Figura 6: Variación acumulada del salario por hora (promedio trimestral) respecto del segundo trimestre de 2016.

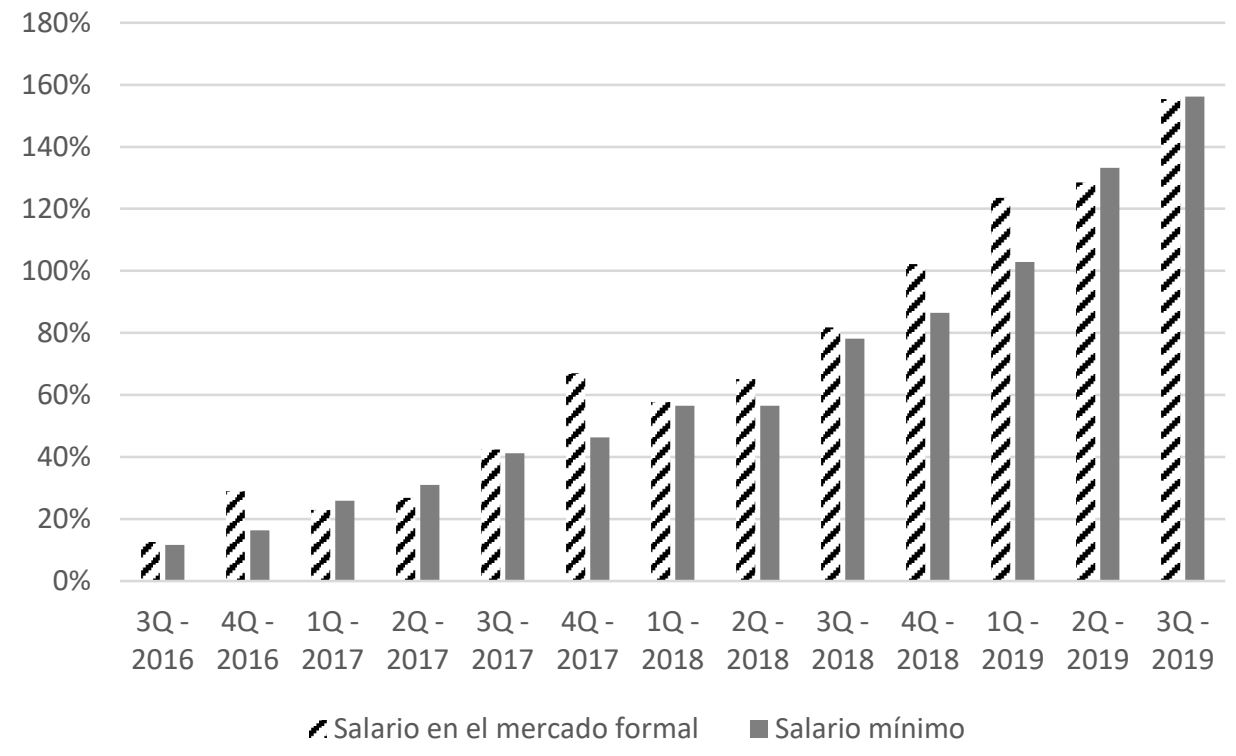

Fuente: elaboración propia a partir de la EPH del INDEC y la Comisión Nacional de Trabajo en Casas Particulares.

Esto podría estar indicando una relación muy cercana entre el sueldo mínimo fijado por la CNTCP y aquel determinado en el ámbito formal. Luego, el vínculo con el salario del mercado informal es más lejano, siendo incierto si en él impacta de manera directa una suba del sueldo mínimo o indirectamente vía un aumento del salario formal ${ }^{18}$. Lo cierto es que directa o indirectamente pareciera ser que los cambios en el sueldo mínimo afectan de manera positiva los ingresos de las empleadas domésticas sin importar el tipo de relación laboral.

En línea con las conclusiones de la autora, el sueldo por hora promedio total suele encontrarse levemente por encima del mínimo ${ }^{19}$, lo que indica que, más allá de sus cambios, su valor nominal sirve como referencia a la hora de pactar contratos laborales.

\footnotetext{
${ }^{18}$ Esto último podría ser poco creíble dado el pequeño tamaño de dicho mercado.

${ }^{19}$ Entre el $3 \%$ y $6 \%$ en casi la mitad de los trimestres analizados, con un promedio de 4\%. Sólo estando por debajo en 3 ocasiones siendo dos de ellas los últimos 2 trimestres tenidos en cuenta. En ellos se encontraron diferencias de alrededor al $9 \%$.
} 
Cabe tener en cuenta que se analizó un período de casi 4 años donde la economía argentina estuvo mayormente en recesión. Esto, como ya se explicó, suele tener un mayor efecto contrayendo la demanda en el mercado informal, lo que contribuye a una baja en los salarios determinados en él. Este podría ser un factor crucial que lleve a resultados diferentes a los explicados por la autora.

Figura 7: Salario mínimo en el empleo doméstico y sus implicancias sobre el salario efectivo

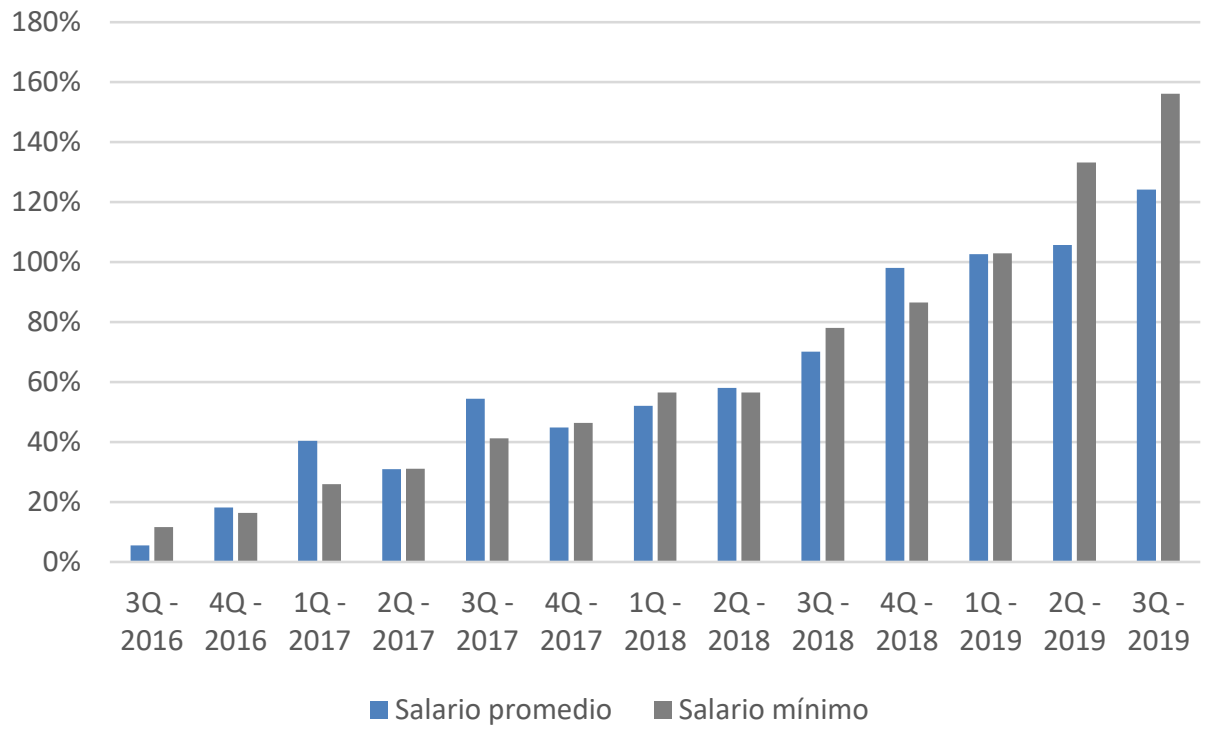

Fuente: Elaboración propia a partir de la EPH del INDEC y la Comisión Nacional de Trabajo en Casas Particulares.

Los datos parecen respaldar este argumento al verse que el salario informal pareciera ser más elástico a la situación macroeconómica del país. En la serie analizada, en períodos de crecimiento económico ha crecido en niveles superiores a los del salario mínimo e incluso aquel fijado en el mercado formal. Por el contrario, en momentos recesivos en general ha seguido por debajo del crecimiento del salario fijado por la CNTCP, destacándose una diferencia significativa en el 2019. Sin embargo, para establecer un vínculo más estrecho entre el crecimiento económico y la evolución del salario en el mercado informal sería prudente utilizar series de mayor longitud.

\section{V.1.2 Pobreza e ingresos}

La Figura 8 podría indicar que existe una cierta correlación entre el índice de productividad y la posición en el nivel de ingresos, lo cual se plasma en que la mayoría de los sectores se ubica próximo a la diagonal imaginaria "sudoeste-noreste" (Schteingart, 2017). En primer lugar, "Servicio doméstico" aparece en el origen como un sector de muy baja productividad y de muy bajos ingresos relativos. Nuevamente, el 
amplio tamaño de la burbuja implica una elevada contribución al empleo nacional (alrededor de 1,7 millones de puestos de trabajo, poco menos del 10\% del total, según datos de Cuenta de Generación del Ingreso e Insumo de Mano de Obra). Las predicciones del modelo clásico de demanda de empleo determinan un vínculo entre la productividad y el nivel de ingreso. En particular, un aumento en la productividad incrementa la demanda de empleo lo que lleva (dependiendo de las elasticidades de la oferta y la demanda) a un aumento del salario y/o de la cantidad de empleo en equilibrio. Asumiendo que la oferta de empleo no es perfectamente elástica, un shock como el explicado llevaría siempre a un aumento en el salario en un mercado competitivo. En el largo plazo con una oferta inelástica la relación sería de uno a uno. Es decir, un aumento de un $1 \%$ en la productividad produciría un aumento de igual magnitud en el salario. Si bien la evidencia empírica muestra una relación positiva entre un aumento en la productividad y un aumento en las remuneraciones a los trabajadores, existen en la realidad factores que producen desviaciones a la norma de largo plazo. Entre ellos se encuentran la presencia de monopsonios, asimetrías de información, heterogeneidad de los trabajadores y políticas económicas "inclusivas" en busca de aumentar los salarios (Van Biesebroeck, 2015). Dicho esto, siendo el sector de empleo doméstico el de menor productividad en la economía, podría ser esperable que se trate de uno con bajos niveles de ingreso en relación con el resto.

Figura 8: Productividad y posición en el nivel de ingreso por sector

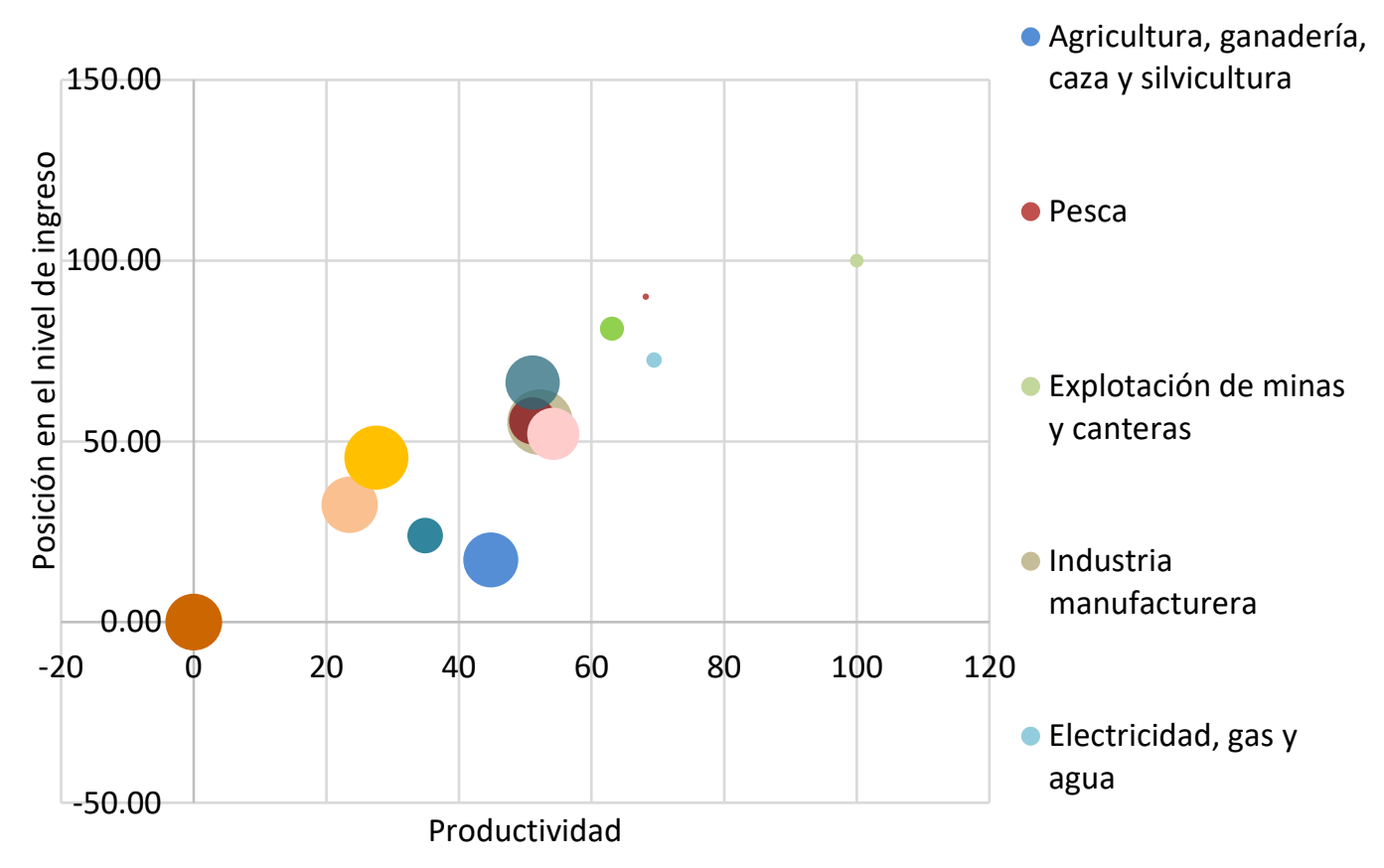

Fuente: elaboración propia en base a Cuenta de Generación del Ingreso e Insumo de Mano de Obra del INDEC. 
Los resultados reflejados en las Figuras 9 y 10 muestran una incidencia en la pobreza notablemente mayor en los hogares donde el jefe es empleado doméstico ${ }^{20}$. Esto se encuentra en consonancia con lo explicado anteriormente acerca del vínculo entre productividad y el nivel de ingreso, ya que un nivel de pobreza por ingresos más alto que la media implica necesariamente una menor capacidad de proveer dinero al hogar por parte de sus miembros. A su vez, se ve lo que pareciera indicar que la tasa en ese grupo de la población suele reaccionar más que la correspondiente al total de aglomerados urbanos (es más volátil). Dicho comportamiento se ve tanto para caídas como aumentos en el indicador. Esto también se evidencia en la Figura 11 que analiza la pobreza medida en personas en lugar de hogares.

Figura 9: Incidencia de la pobreza en hogares

si el jefe de hogar es empleado doméstico

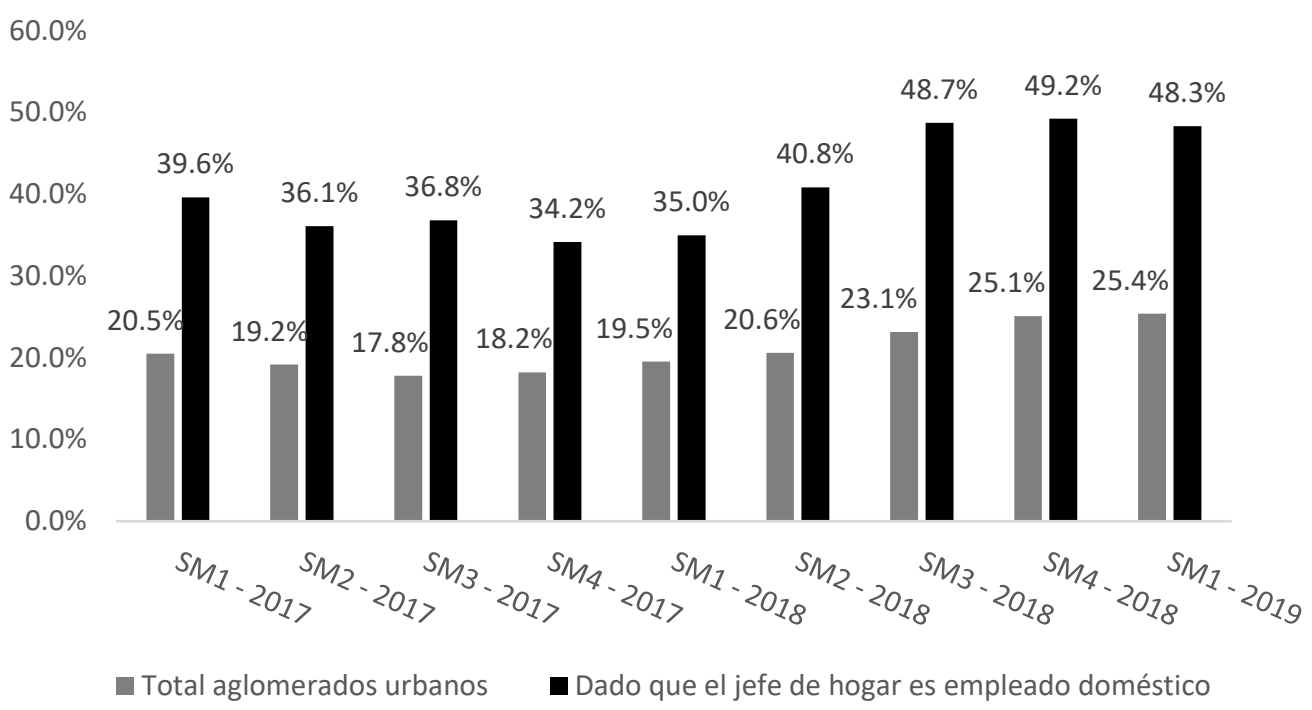

Fuente: elaboración propia en base a la EPH y mediciones de la Canasta Básica Total del INDEC.

Un factor que podría contribuir a ello es la ya nombrada necesidad de recurrir al empleo doméstico por parte de los más vulnerables. Esto podría provocar que, ante una situación de aumento de la pobreza y/o del desempleo, muchos trabajadores de baja calificación (sobre todo las mujeres) se vean obligados a buscar trabajo en este mercado ante la dificultad de conseguir algo mejor para ellos y sus familias ${ }^{21}$. Con lo cual, al aumentar la

\footnotetext{
${ }^{20}$ Estudios en Uruguay y Chile también encuentran una incidencia en la pobreza considerablemente superior para los hogares integrados por empleados domésticos (Batthyany, 2012; Ministerio de Trabajo y Seguridad Social, 2019; Ordenes Carvajal, 2016).

${ }^{21}$ Blundell et al. (2016) encuentran que uno de los canales de ajuste más importantes ante una situación de caída en los ingresos que provee el hombre es el aumento de la participación laboral de su esposa. A su vez, el trabajo de Berniell et al. (2019) describe cómo las madres que participan del mercado de trabajo suelen hacerlo en labores que les brinden cierta flexibilidad horaria para poder atender las necesidades de su propio
} 
población en estado de vulnerabilidad que se dedica a esta labor se presiona aún más a la suba en la pobreza para los empleados domésticos. Un fenómeno similar podría suceder en caso contrario. Aquellos que utilizan este tipo de trabajos como resguardo, al mejorar la situación económica en el país suelen ir a buscar otras opciones que mejoren su bienestar. Esto "libera" mercado para los que no tienen esa posibilidad mejorando su situación y ayudando así a una disminución mayor en la tasa de pobreza.

Por otro lado, otra razón que podría explicar este fenómeno es que gran parte de los trabajadores del empleo doméstico ${ }^{22}$ y sus familias tengan un nivel de ingreso próximo a la línea de pobreza. Esto provocaría que modificaciones en la misma tengan un impacto mucho mayor para ellos en comparación con otros sectores de la economía. De hecho, el siguiente histograma pareciera indicar esto mismo. En él puede verse la línea negra que representa el promedio de la línea de pobreza para los hogares donde el jefe es empleado doméstico para el primer semestre del 2019. El gráfico parece indicar que la mayoría de los empleados domésticos que son jefes de hogar tienen un nivel de ingreso familiar cercano a dicha cifra. Es decir, modificaciones en la línea de pobreza impactan dejando a muchos de esos hogares debajo o por encima de ella. En consecuencia, podría justificarse una volatilidad mayor en la tasa de pobreza correspondiente a estos hogares en comparación con la que le corresponde a toda la sociedad.

Figura 10: Gráfico de densidad de hogares donde el jefe es empleado doméstico por ingreso total familiar. Correspondiente al primer semestre del 2019

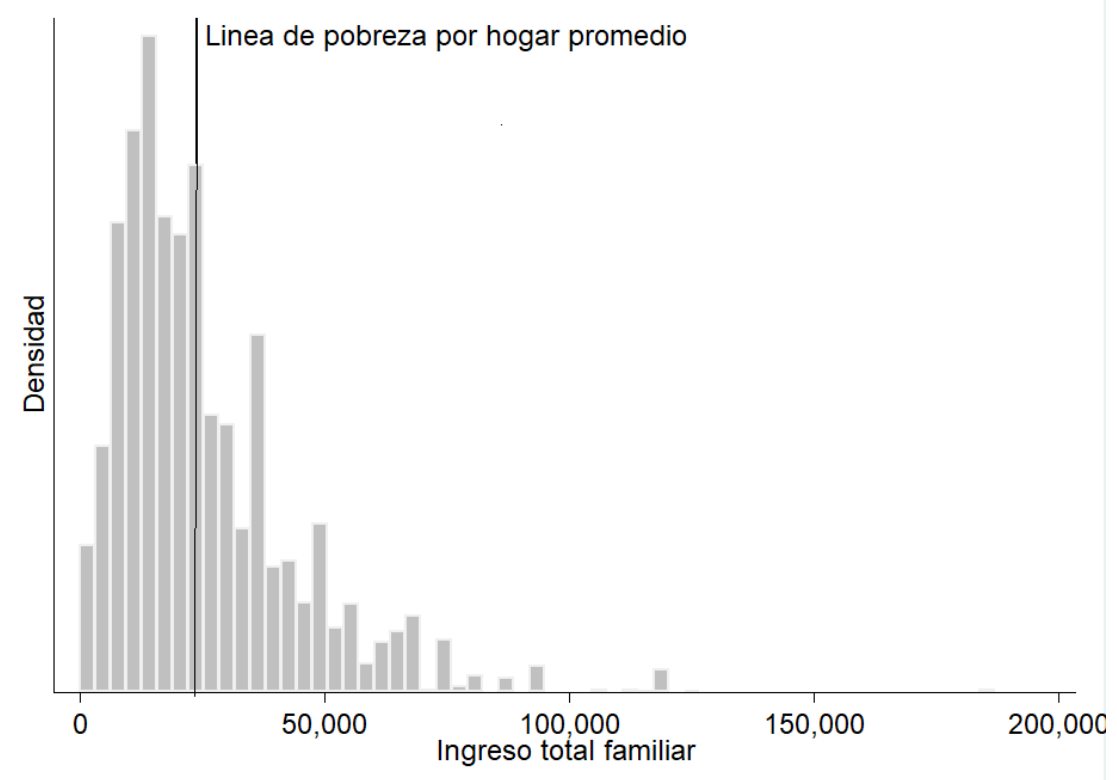

Fuente: elaboración propia en base a la EPH y mediciones de la Canasta Básica Total del INDEC.

\footnotetext{
hogar. Esto las lleva en muchos casos al mercado informal, el cual brinda este tipo de facilidades. Estos resultados podrían indicar que, ante una caída en los ingresos del hogar, la madre es la que debe aumentar su carga laboral, terminando en trabajos como el empleo doméstico que le permiten cierta flexibilidad a pesar de la precariedad que conlleva.

${ }^{22}$ Se habla de aquellos que son jefes de hogar.
} 
Debería tenerse en cuenta que el período de referencia tomado para este gráfico de densidad le corresponde una estimación de la pobreza de las más altas para la Argentina en los últimos años. Con lo cual, podría intuirse que la línea de pobreza promedio donde el jefe de hogar es empleado doméstico se encuentra en una posición relativamente alta en comparación con los ingresos de esas familias. En períodos no caracterizados por una incidencia en la pobreza marcadamente superior a lo habitual en nuestro país, es probable que la misma se posicione más a la izquierda de la distribución. Esto implica que la conclusión previa se sostendría ya que la línea de pobreza se ubicaría usualmente en la cola de la distribución, donde se encuentra la mayor cantidad de hogares.

Con datos al cuarto trimestre del 2018 la EPH muestra que el 44,85\% de los empleados domésticos son jefes de hogar ${ }^{23}$. Esto marca la importancia de las cifras presentadas, las cuales debieran verse con gran preocupación. Schteingart (2017) encuentra resultados similares en su estimación de la pobreza correspondiente al segundo trimestre del 2016, reflejando que el servicio doméstico ${ }^{24}$ es el sector con mayor incidencia en la pobreza del país seguido muy de cerca por la construcción. Siendo este último un sector al que deben recurrir los más necesitados y de baja calificación, similar al caso de las empleadas domésticas, es probable que existan muchos hogares con integrantes que se dediquen a ambos rubros. Por ello, seguramente exista una cantidad de casos considerable donde el jefe de hogar trabaja en la construcción y algún otro integrante en el servicio doméstico. De esta manera, la vulnerabilidad de aquellos que trabajan en el rubro que aquí se estudia podría ser aún mayor que lo reflejado por su incidencia en la pobreza analizada en la Figura 9.

Figura 11: Incidencia de la pobreza en personas si el jefe de hogar es empleado doméstico (medida en semestres móviles)

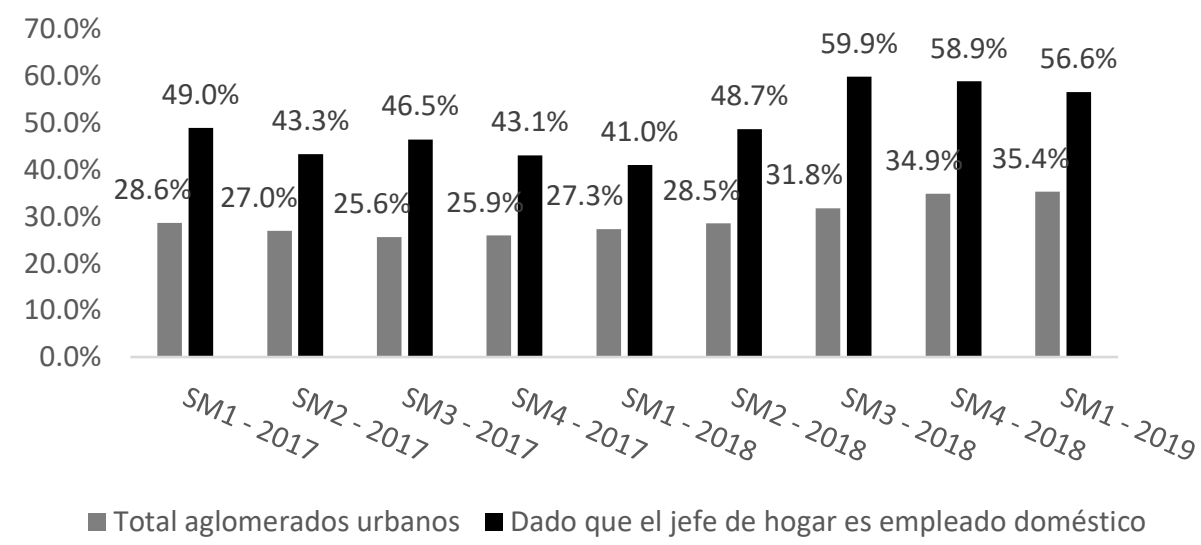

Fuente: elaboración propia en base a la EPH y mediciones de la Canasta Básica Total del INDEC.

\footnotetext{
${ }^{23}$ Esto es similar a los casos uruguayo y chileno en donde se llega al $40 \%$ y $44 \%$ respectivamente (Ministerio de Trabajo y Seguridad Social, 2019; Órdenes Carvajal, 2016).

${ }^{24}$ Notar que la definición utilizada en este trabajo para el empleo doméstico no es la misma.
} 
A continuación, podemos ver que al analizar la pobreza por personas los indicadores manifiestan una situación más preocupante. La diferencia con respecto a la totalidad de los aglomerados urbanos podría verse agravada porque los hogares donde el jefe es empleado doméstico tienen una cantidad de miembros mayor a la media ${ }^{25}$. Es decir, una mayor cantidad de personas en el hogar agudiza la brecha en la incidencia de la pobreza ya reflejada en los datos a nivel hogar.

A partir de los resultados encontrados se busca realizar un estudio más preciso de la situación de vulnerabilidad de aquellas familias relacionadas al empleo doméstico. En el gráfico siguiente se analiza cómo varía la tasa de pobreza en personas al aumentar el salario por hora de los que brindan estos servicios. Si bien parecen modestos los resultados al implementar los ajustes, hay que tener en cuenta la dificultad que conlleva una estrategia en busca de reducir la pobreza, y que todo avance por más pequeño que sea es importante. Por otro lado, aunque la tasa a nivel país no progrese demasiado, sí se encuentra una mejora considerable en la situación de los empleados domésticos y sus familias. Se ve que un aumento del $10 \%$ en el ingreso por hora de los empleados domésticos provoca una disminución de casi el $2 \%$ en la tasa de pobreza para aquellas personas donde su jefe de hogar es empleado doméstico. Más aún, un aumento del $20 \%$ genera una disminución mayor al 3\% y baja la cifra nacional en un 0,35\%. Por último, si se ve un avance notable al incrementar el sueldo por hora un 50\%. En ese caso la tasa para el total de los aglomerados urbanos cae un $0,76 \%$ y para el caso particular estudiado más de un $8 \%$.

Figura 12: Incidencia de la pobreza ante ajustes en el salario por hora de los empleados domésticos. Correspondiente al primer semestre del 2019.

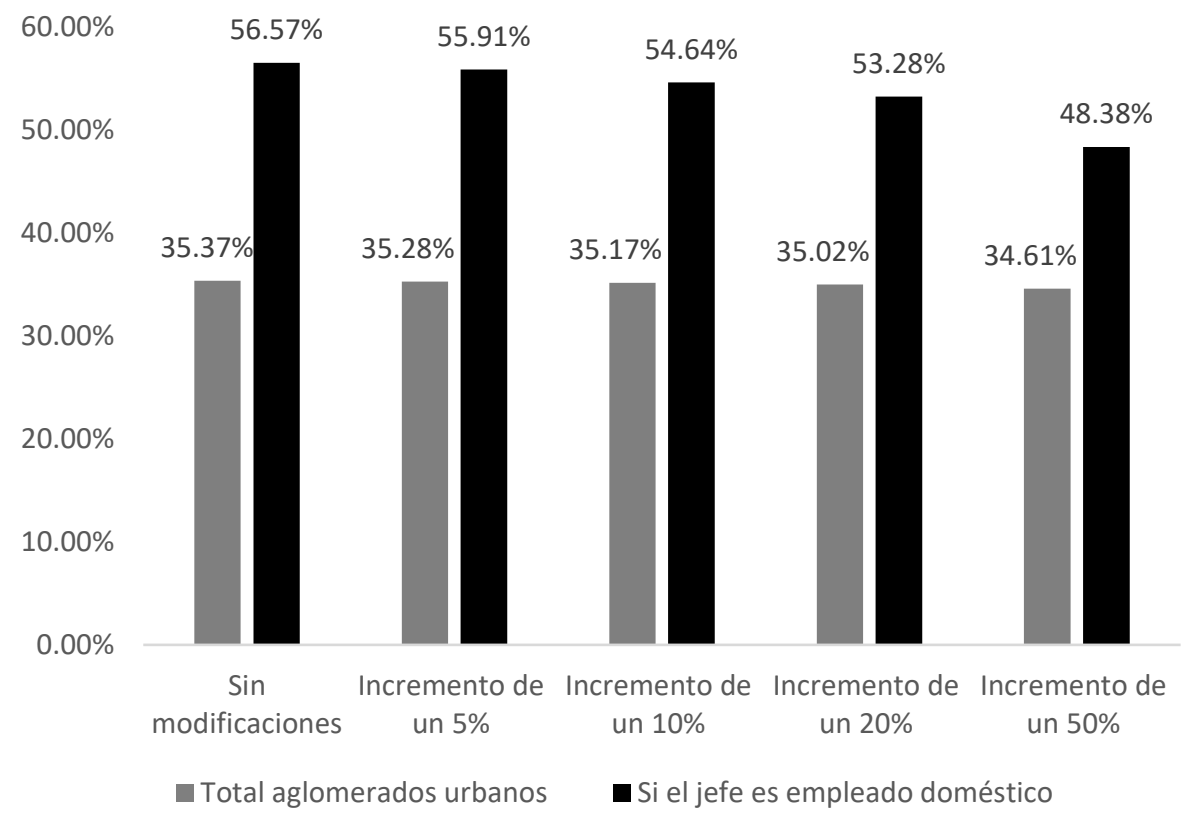

Fuente: elaboración propia en base a la EPH y mediciones de la Canasta Básica Total del INDEC.

${ }^{25}$ Nuevamente se trata de información obtenida de la EPH correspondiente al cuarto trimestre del 2018. 
Cabe notar que al incrementar el sueldo por hora de los empleados domésticos un $10 \%$ aumenta sus ingresos mensuales en un promedio de casi 700 pesos, aproximadamente un $6 \%$. Ante un aumento del $50 \%$ ellos suben cerca de 3350 pesos, alrededor de un $30 \%$. Luego, a continuación, se ve qué sucede si cada empleado doméstico recibiera un subsidio del Estado.

La Figura 13 permite ver cómo el accionar directo del Estado podría mejorar el bienestar de las familias relacionadas al empleo doméstico. También demuestra lo importante que puede ser una política económica sectorial que busque incrementar los ingresos de dicho sector en disminuir el nivel de pobreza de toda la sociedad. Especialmente, si uno logra incrementar los ingresos mensuales de los empleados domésticos en 2000 pesos mediante transferencias (aproximadamente un 18\%) permitiría bajar la cantidad de personas debajo de la línea de pobreza en casi 0,3\%. Dicho aumento sería equivalente a lograr una suba de alrededor del $30 \%$ en el salario horario. Al incrementar el ingreso en 4000 pesos (un 36\%) los resultados son más alentadores. La tasa para el grupo de estudio cae más de un $8 \%$ y la correspondiente a nivel nacional lo hace en casi un $1 \%$. Por supuesto que no hay una única forma de lograr esto y habría que hacer un estudio cuidadoso para encontrar la más eficiente. Sin embargo, la forma más sencilla brindando subsidios seguramente sea de utilidad en el corto plazo ${ }^{26}$.

Figura 13: Incidencia de la pobreza en personas ante transferencias estatales a los empleados domésticos. Correspondiente al primer semestre del 2019

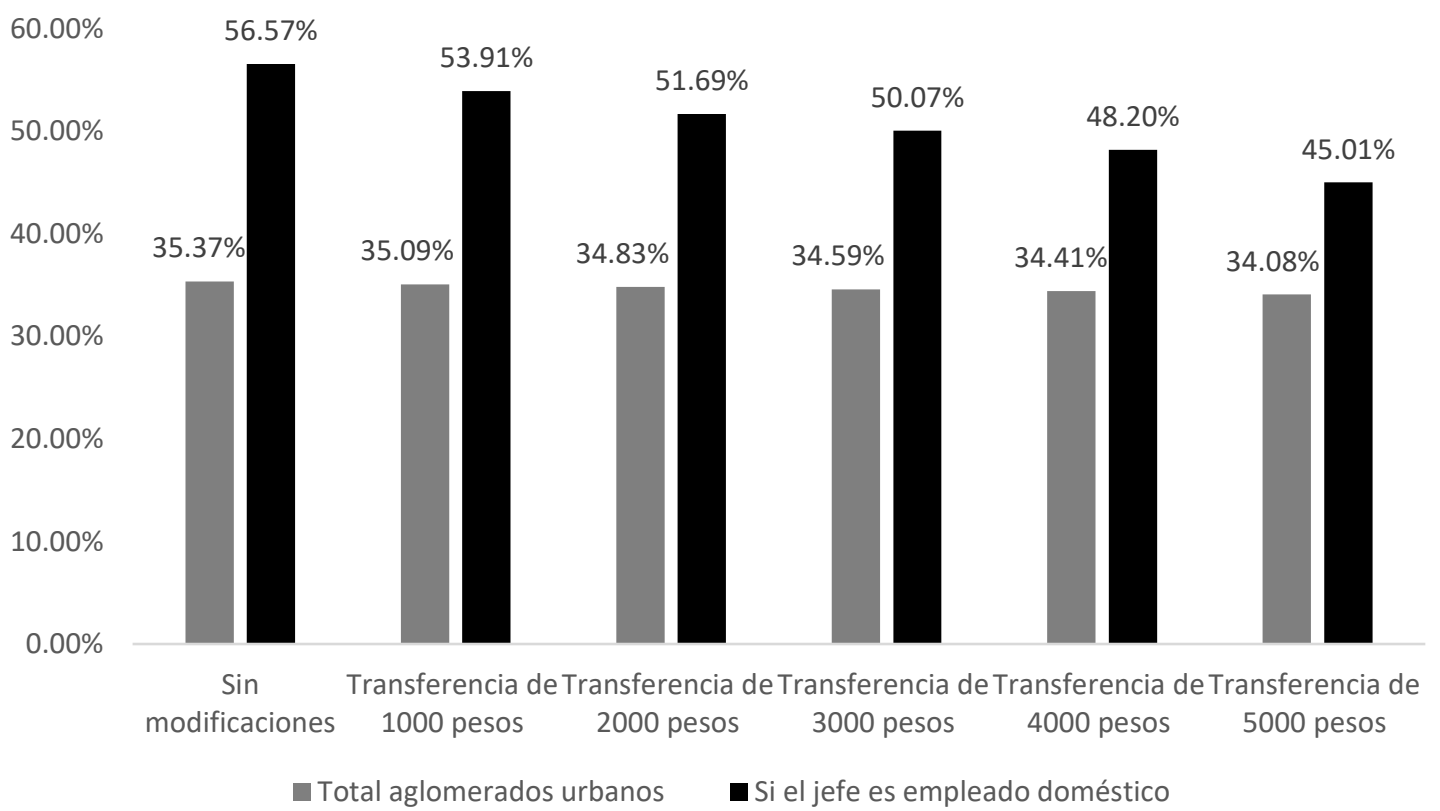

Fuente: elaboración propia en base a la EPH y mediciones de la Canasta Básica Total del INDEC.

\footnotetext{
${ }^{26}$ Cabe aclarar que no se están analizando los efectos indirectos que una política como la comentada podría provocar en la oferta de horas de trabajo y en términos de equilibrio general.
} 
Las cifras obtenidas nos indican que políticas económicas que generen un aumento en el nivel de ingreso de los trabajadores del empleo doméstico tienen un impacto sustancial en disminuir la incidencia de la pobreza en ellos y sus familias. Más aún, esto genera una baja moderada en la tasa a nivel país. No debería menospreciarse este resultado ya que indica que políticas orientadas en este sentido pueden ser útiles dentro de un programa integral para reducir la pobreza en nuestra sociedad. Es decir, si bien es moderada, constituye un avance significativo en un área donde la Argentina se encuentra sin un rumbo claro desde hace muchos años. Incluso, por medio de transferencias un resultado en esta óptica probablemente pueda ser obtenido a un costo mucho menor que otras alternativas, al menos en el corto plazo. En el apéndice puede encontrarse una tabla que resume los resultados encontrados de esta estimación.

\section{V.1.3 Género e inmigración}

Se estima a partir de la EPH (4Q 2018) que el 98,4\% del empleo doméstico en la Argentina es efectuado por mujeres. Este resultado está en línea con el 97,7\% obtenido por la OIT (2013) para el año 2006, aunque por encima del 92\% correspondiente a América Latina y el Caribe en 2010. Esto deja en evidencia la mayor dificultad en la inserción laboral formal para el género femenino de bajo nivel educativo. En el gráfico 1 vemos que hay una fuerte relación entre la formalidad del sector y el nivel de ingreso. Podría pensarse que, al ser un sector encabezado principalmente por mujeres con bajos niveles educativos (sólo el 31,14\% finalizó el polimodal/secundario en comparación con un $53,15 \%$ para el resto de los trabajadores ${ }^{27}$ ), tiene sentido que sea un sector muy informal debido a la existencia de barreras de entrada al mercado formal. Al predominar la informalidad en el empleo doméstico encaja dentro de este análisis que sea un sector caracterizado por una importante incidencia en la pobreza y bajos ingresos.

Figura 14: Participación de los extranjeros en el empleo doméstico.

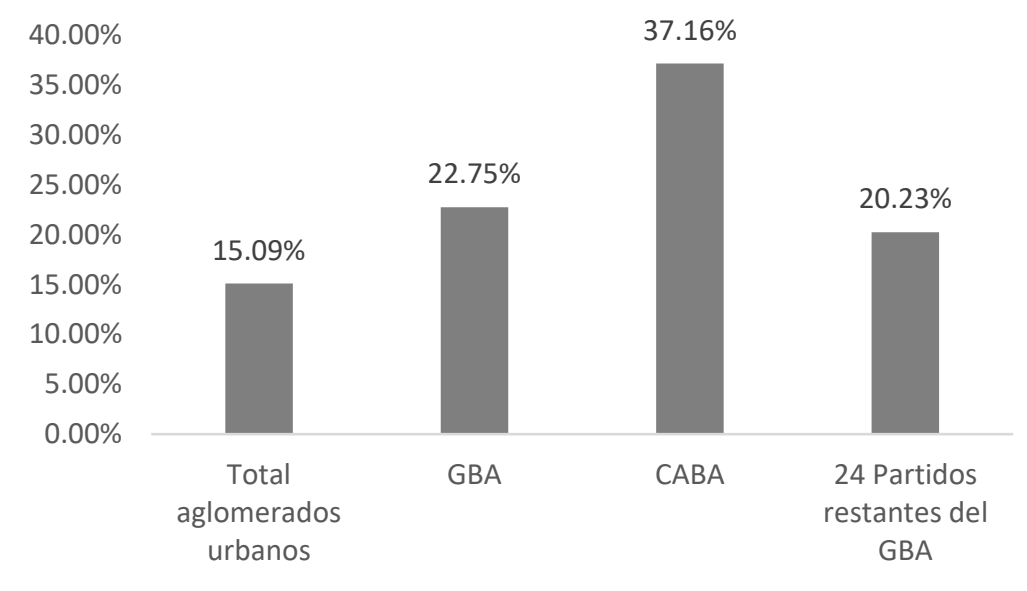

Fuente: elaboración propia en base a la EPH correspondiente al cuarto trimestre del 2018.

\footnotetext{
${ }^{27}$ Más aún, sólo un 4,7\% pudo terminar un nivel terciario o mayor mientras que para el remanente de trabajadores la ratio es de un $25,3 \%$.
} 
Por último, la Encuesta Permanente de Hogares permite abordar el tema de los inmigrantes. La relevancia de estos concuerda con la literatura presentada ya que un $15,09 \%$ de los empleados domésticos en nuestro país provienen del extranjero, mucho mayor que en el resto de los rubros donde los extranjeros representan solamente el $5,92 \%$ del total. Incluso, si se tuviera en cuenta quiénes son hijos de inmigrantes, sobre todo de países limítrofes, la relación probablemente sea mayor.

La Figura 14 muestra que, para el Gran Buenos Aires, la tasa sube a un 22,75\%. Pero al desagregar esa muestra se llega a que en la Ciudad de Buenos Aires los extranjeros representan un $37,16 \%$ de los empleados domésticos. Cabe resaltar que dicha cifra está debajo de la encontrada por Ceriani et al. (2009) quienes utilizaron información del censo del 2001. Este resultado probablemente haya sido diferente ya que desde entonces se revirtieron ciertas condiciones que, según la literatura del tema, alentaban un incremento en las corrientes migratorias provenientes de países limítrofes. En particular, se menciona como causante de ello a la persistente apreciación del tipo de cambio en los 90. Dicho fenómeno mejoraba el nivel de ingreso en pesos lo que alentaba a muchos provenientes de países vecinos a migrar a la Argentina. Sobre todo, aquellas mujeres migrantes no calificadas debían recurrir al empleo doméstico como una de sus pocas opciones, ampliando la participación en el sector de los extranjeros ${ }^{28}$.

\section{V.2 La demanda de empleo doméstico}

A pesar de que el $11 \%$ de los hogares reciben servicio de empleo doméstico (ENES), esto varía dependiendo de sus características y las de sus integrantes ${ }^{29}$. Aquí se busca explicar cuáles de ellas pueden ser relevantes al determinar la demanda de estos servicios.

\section{V.2.1 Ingresos}

Existe vasta literatura que respalda que un mayor nivel de ingreso aumenta las posibilidades de consumo de bienes y servicios en la gran mayoría de los casos. Por ello, esta probablemente sea la cuestión central en la decisión de demandar las prestaciones que aquí se analizan. En esa línea, a través de los datos brindados por la ENES, puede verse que el ingreso medio per cápita de los hogares que contratan servicios de empleo doméstico es un $60,6 \%$ mayor a aquellos que no lo hacen. Por lo tanto, existe un diferencial notable en el nivel de ingresos, lo que refleja un mayor poder de compra de bienes y servicios.

La tendencia hacia un mayor acceso a este tipo de prestaciones se puede ver con claridad en la Figura 15. Esta muestra un mayor porcentaje de hogares que contratan empleo doméstico a medida que se sube en los deciles de ingreso.

\footnotetext{
${ }^{28}$ La OIT (2015) estima para el 2013 que el 38\% de las mujeres migrantes en América Latina se dedica al empleo doméstico. Esto pone en perspectiva la importancia del rubro para las inmigrantes en la región.

${ }^{29}$ Esta cifra se encuentra en concordancia con lo estimado por Bertranou \& Casanova (2013) a partir de la ENGHO 2004-2005 y por encima del 9\% obtenido para Uruguay (Ministerio de Trabajo y Seguridad Social, 2019).
} 
Un resultado interesante es aquel que nos refleja la Figura 16. En el mismo se clasifican los hogares en base a un criterio adicional. Al igual que antes se utilizan los deciles de ingresos, pero también se los ordena según la posición en la escala socioeconómica en que los encuestados creen estar. Sucede que aquellos que se autoperciben en una posición social baja contratan menos empleo doméstico que los que efectivamente están en la parte inferior de la escala de ingresos. Los que consideran estar mejor relativamente que el resto de la sociedad suelen contratar más en relación con los que en verdad se encuentran en los mayores deciles de ingreso. Esto parece indicar que la autopercepción de la posición social marca una tendencia levemente más clara con relación a la ubicación real. Por lo tanto, es posible que sea importante en la decisión de consumo de estos servicios la creencia de que uno está en una mejor o peor posición que otros.

Figura 15: Demanda de servicio doméstico por decil de ingreso

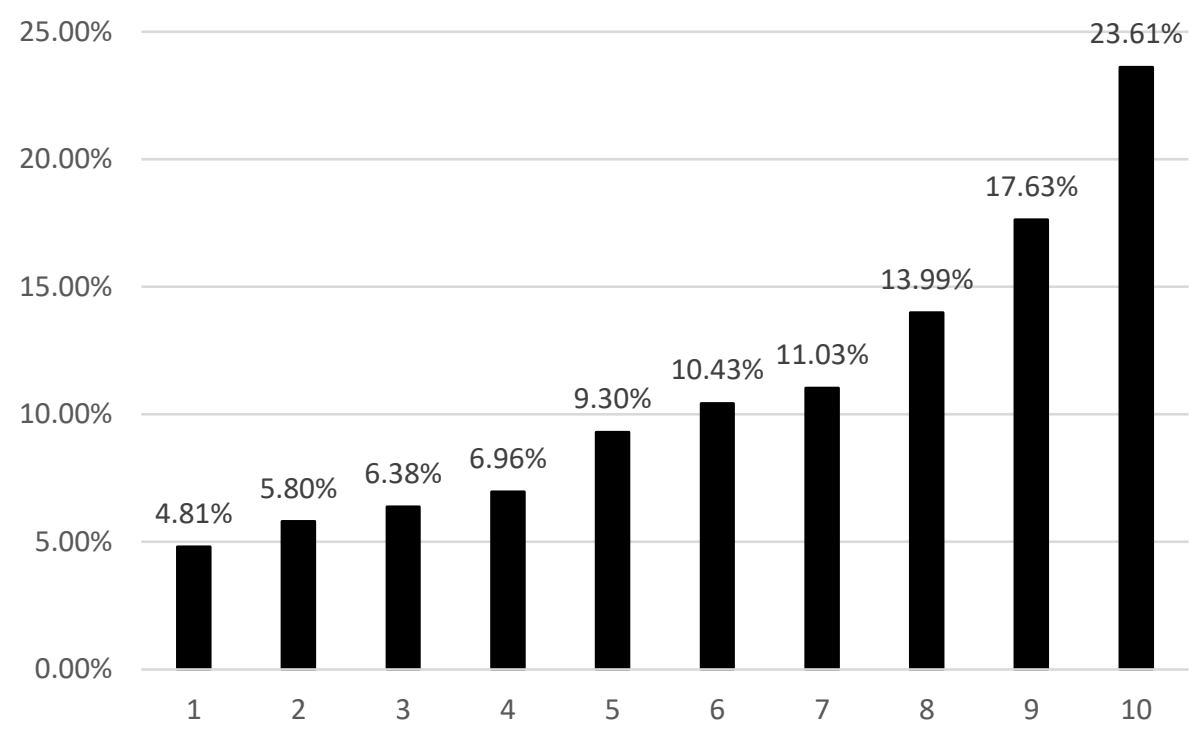

Fuente: elaboración propia en base a la Encuesta Nacional sobre la Estructura Social (ENES). 
Figura 16: Demanda de servicio doméstico posición social autopercibida vs escala de ingresos ${ }^{30}$

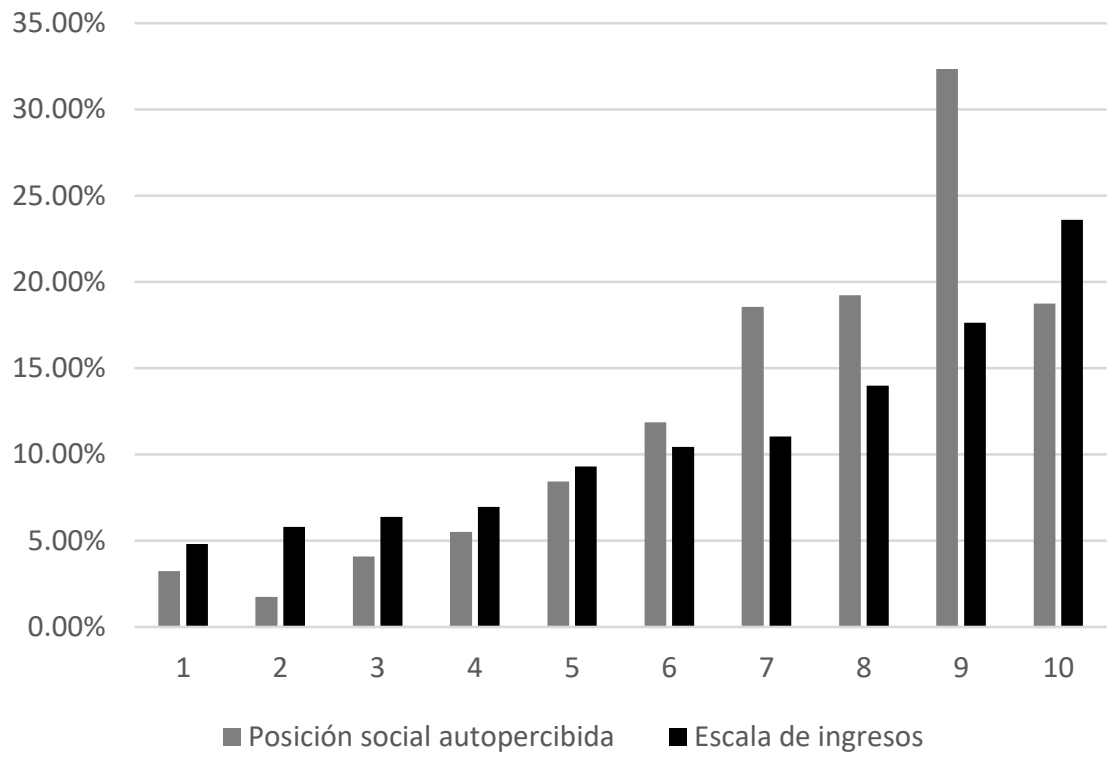

Fuente: elaboración propia en base a la Encuesta Nacional sobre la Estructura Social (ENES).

Más aún, al ser preguntados dentro de qué clase social se ubicarían la tendencia es más evidente. Dicho esto, y habiendo analizado el caso de la posición social auto percibida, se podría concluir que, además de los ingresos que uno recibe, un componente muy importante en la demanda de este tipo de servicios, y probablemente de muchos otros, es la creencia de cómo está uno económicamente en relación con el resto de la sociedad. En la Figura 17 se muestra que, de aquellos que creen pertenecer a la Clase Alta, un $52,74 \%$ contratan servicio de empleo doméstico mientras que los que se consideran miembros de la Clase Baja solo lo hacen en un 3,88\%.

\footnotetext{
${ }^{30}$ Es debido resaltar que los resultados obtenidos de los gráficos 15 y 16 se mantienen utilizando deciles de ingreso per cápita. Aquí se exponen de otra manera para facilitar la intuición gráfica del lector.
} 
Figura 17: Demanda de servicio doméstico por clase social auto percibida ${ }^{31}$

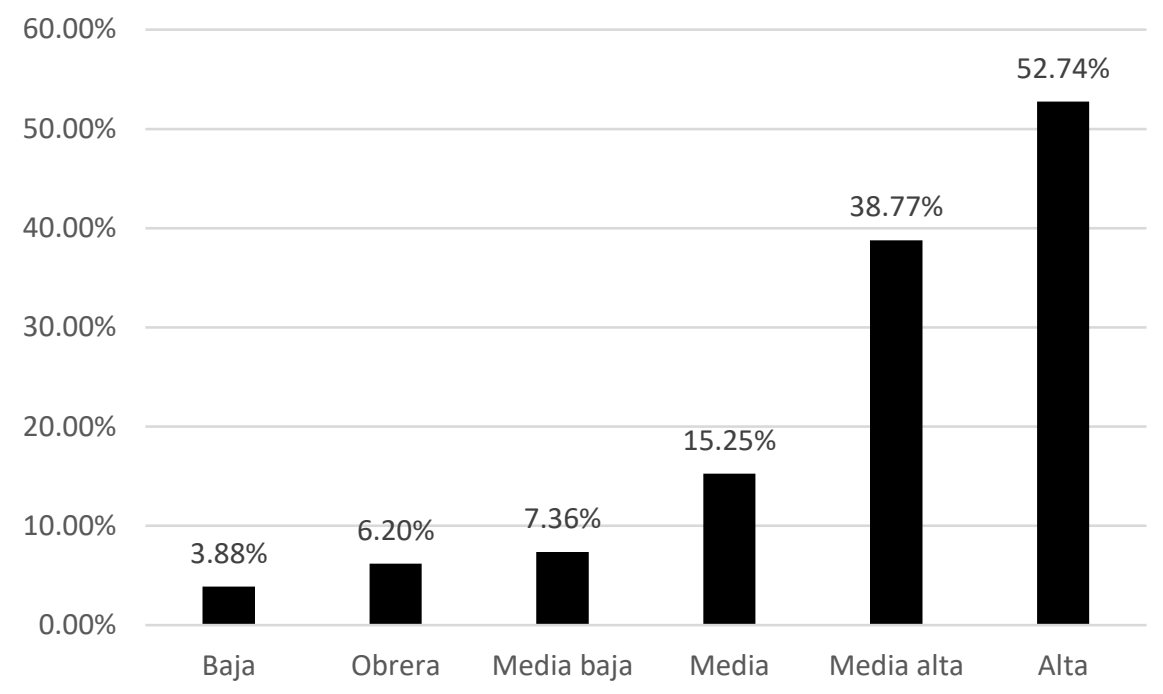

Fuente: elaboración propia en base a la Encuesta Nacional sobre la Estructura Social (ENES).

El resultado encontrado sobre una mayor demanda de empleo doméstico en aquellos que consideran estar en una posición social relativamente alta podría relacionarse con la literatura sobre consumo posicional. La misma sugiere que el estatus es un factor importante en el bienestar de los individuos y que hay ciertas características observables que lo determinan en cada sociedad ${ }^{32}$. De esta forma, los que se consideran erróneamente en una situación más favorable "compiten" con quienes la ostentan, debiendo incurrir en un mayor gasto en bienes que señalicen un alto estatus. Esto se da no sólo por la vara impuesta en el decil que se adjudican, sino por la posible carencia de otras características observables en ese sentido. Es decir, el consumo de bienes que señalicen un cierto estatus podría ser utilizado también para compensar esa falencia. Lo encontrado parece indicar que el acceso al servicio doméstico podría constituir un canal de señalización en este sentido. De hecho, el papel del estatus en la demanda de estos servicios ya fue comentado en la literatura (Anderson, 2001).

En cuanto a la composición del hogar, aquellos hogares que reciben como ingreso una jubilación, muestran un acceso al servicio doméstico del 14,97\% mientras que el resto sólo un $9,21 \%$. Por supuesto esto está ligado a la necesidad del cuidado de ancianos o gente mayor y a la menor capacidad para realizar tareas del hogar de aquellos que son mayores (jubilados en este caso). Incluso puede estar relacionado con el menor tiempo disponible para hacerse cargo de otras tareas por parte de aquellos miembros del hogar

\footnotetext{
${ }^{31}$ Notar que es el encuestado quien se clasifica dentro de las opciones que provee la encuesta.

32 Las preferencias por estatus podrían explicarse desde varios mecanismos. Entre ellos, se han estudiado la posibilidad de beneficios derivados de las relaciones sociales y el impacto negativo de un menor ingreso/consumo relativo a otros (Heffetz \& Frank, 2011).
} 
que deben atender las necesidades de los adultos mayores. Esto toma relevancia ya que un $41,36 \%$ de los hogares que acceden al servicio doméstico cuentan con una jubilación como parte de sus ingresos. En caso contrario, un $28,88 \%$ de ellos recibe ese tipo de prestaciones.

Por último, se encuentra una relación positiva entre el acceso al crédito y al servicio doméstico en el hogar. Según los datos de la ENES, de los hogares donde algún miembro obtuvo un préstamo en los 5 años previos a la encuesta un 13,84\% accedían a dicha prestación mientras que en caso contrario solo lo hacían un $9,81 \%$. A su vez, se verifica un comportamiento similar pero más evidente al analizar la capacidad de ahorro. De aquellos que manifiestan que sus ingresos les alcanzan incluso para ahorrar, un $25,47 \%$ contratan empleo doméstico. En los casos en que no pueden ahorrar y los que no les alcanzan sus ingresos, un $10,62 \%$ y un $4,61 \%$ pudieron acceder a este servicio respectivamente 33 . Esto puede reflejar que aquellos con mayor capacidad de obtener asistencia financiera o de ahorrar pueden afrontar gastos cuasi fijos con menor riesgo ante los ciclos de la economía, lo que deriva en un sendero de consumo menos volátil. Por supuesto estos aspectos tienen un estrecho vínculo con el nivel de ingresos de cada hogar.

\section{V.2.2 Ubicación geográfica}

La localización del hogar está fuertemente ligada con el ingreso ${ }^{34}$, la desigualdad, la pobreza y el desempleo. Esto se debe a que las regiones pueden diferir en términos de retribución económica a sus pobladores, cantidad de oferta de trabajo no calificada (la que nos incumbe en este caso), el nivel de pobreza que deriva en una mayor cantidad de gente marginada que recurre al empleo doméstico y el diferencial de ingresos que tienen los más ricos en relación con los más pobres.

En la Figura 18 se ve cómo regiones que se asocian a un mayor poder adquisitivo promedio como lo son la Pampeana y Centro son las que más acceden al servicio de empleo doméstico ${ }^{35}$. Por otro lado, Cuyo que es una de las de menor ingreso medio per cápita por hogar ${ }^{36}$ y también es aquella con la menor tasa de acceso a estas prestaciones. A pesar de ello, se presentan 3 casos que vale la pena analizar. Primero, surge la pregunta de por qué la Patagonia al ser la que se adjudica el mayor ingreso medio per cápita por hogar tiene una de las menores tasas en el gráfico. Una razón que podría explicar esto es que se caracteriza por ser una región con bajo nivel de pobreza con relación al resto y posiblemente una oferta de mano de obra no calificada también baja comparada con el Gran Buenos Aires o Centro ${ }^{37}$.

\footnotetext{
33 También se verifica que es notoriamente más frecuente la capacidad de ahorrar en los hogares que acceden al empleo doméstico contra los que no lo hacen. Lo mismo sucede en cuanto al acceso al mercado financiero, aunque la diferencia es menor.

${ }^{34}$ Cuando se haga referencia al ingreso per cápita regional o por hogar, este no está ajustado por índices de precios regionales.

${ }^{35}$ Recurrir al gráfico 2 del apéndice para más información acerca del ingreso per cápita por región.

36 Un 55\% menor al más alto correspondiente a la Patagonia.

${ }^{37}$ En línea con esto, Birgin (2009) estima que la región patagónica es aquella con menor proporción de trabajo doméstico entre las ocupadas.
} 
Figura 18: Demanda de servicio doméstico por región

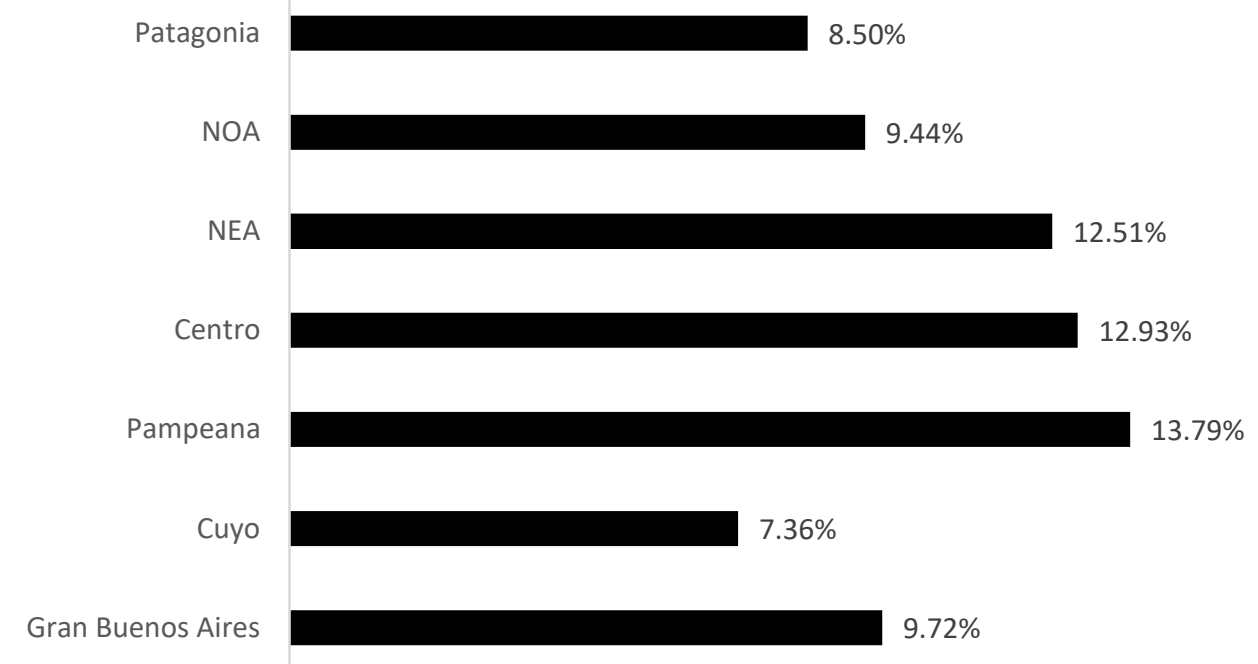

Fuente: elaboración propia en base a la Encuesta Nacional sobre la Estructura Social (ENES).

Luego está el NEA que a pesar de tener un nivel de ingresos menor al resto (un $61 \%$ menor a la Patagonia según datos de la ENES) le corresponde una de las mayores tasas de acceso al servicio doméstico. Un motivo que podría explicar esto es que suele tratarse de la región con mayor tasa de pobreza y con una clara diferencia en comparación al resto según los datos que provee el INDEC cada semestre. Teniendo los más desafortunados pocas oportunidades para incorporarse al mercado de trabajo y sobre todo al formal, para las mujeres una de sus mejores opciones es dedicarse al empleo doméstico mientras que los hombres del hogar suelen buscar todo tipo de trabajos de baja calificación en la construcción y tareas agrícolas, entre otros. A su vez, se trata de la región con mayor tasa de hogares donde el Principal Sostén del Hogar (aquel que trae la mayor cantidad de ingresos al hogar, sin importar si es jefe o no) es mujer, alcanzando el 38,8\%. Entonces, el hecho de tener una gran parte de su población en la pobreza y que muchos de esos hogares probablemente tengan a una mujer como Principal Sostén del Hogar, para quienes el servicio doméstico es un recurso muy importante, podría estar teniendo un efecto más que compensador en el hecho de que esta región tenga un nivel de ingreso per cápita bajo.

El último caso por analizar es el del Gran Buenos Aires que es la segunda región en términos de ingreso per cápita y aun así presenta una tasa de empleo doméstico por hogar modesta con relación a otras no tan ricas. Aquí vamos a hacer una salvedad muy importante: si bien en la región se ve una tasa del 9,72\% al separar la Ciudad de Buenos Aires $\mathrm{y}$, por otro lado, los 24 partidos de la provincia relevados en la encuesta, les corresponden respectivamente una tasa del $17,64 \%$ y $6,45 \%$. Es una diferencia más 
que relevante que puede deberse a un diferencial de ingresos. Concretamente, la media de ingreso per cápita por hogar es un $29 \%$ menor en los restantes 24 partidos en comparación con la Ciudad Autónoma de Buenos Aires. A su vez, el mayor nivel de pobreza de dichos partidos en relación con esta última ${ }^{38}$ lleva a que, dada la cercanía y el diferencial de ingresos, muchos de los más desafortunados recurran al empleo doméstico trasladándose a ella. Esto último disminuye la proporción de hogares que tienen acceso al servicio doméstico en el resto del Gran Buenos Aires y permite cubrir una necesidad en la ciudad que posiblemente no podría de otra forma al no generarse su propia oferta de trabajadores no calificados orientados al empleo doméstico. Aplicando esta pequeña corrección el gráfico debería quedar como se muestra en la Figura 19.

Figura 19: Demanda de servicio doméstico por región

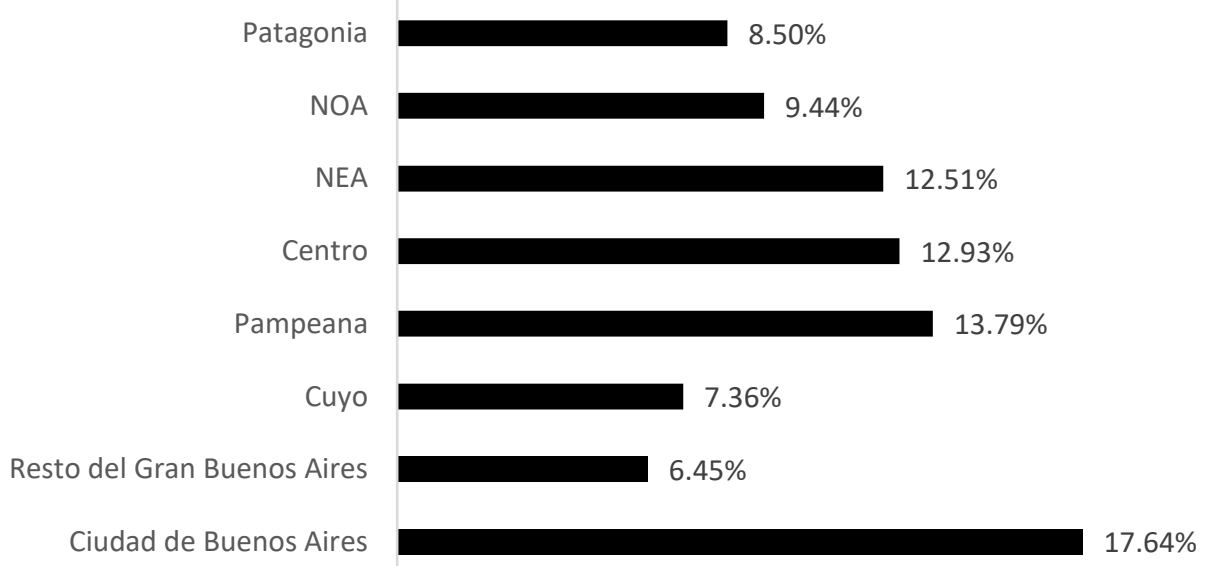

Fuente: elaboración propia en base a la Encuesta Nacional sobre la Estructura Social (ENES).

Un enfoque muy interesante es analizar por tipo de barrio en que se ubica la vivienda. La Figura 20 muestra nuevamente un vínculo muy importante entre el nivel de ingresos y la contratación de empleo doméstico. Es impactante el caso de las zonas de quintas residenciales donde el $83,75 \%$ de los hogares acceden al servicio. La tasa es tanto mayor al resto de los barrios ya que se trata de aquel de mayor ingreso medio per cápita y con una diferencia con el segundo (zona rural urbana) del 60\%. A pesar de esto, su relevancia puede no ser tal en el total del sector ya que sólo un $0,47 \%$ de los hogares que contratan empleo doméstico se encuentran en zonas de quintas residenciales. En los barrios privados cerrados, donde el ingreso medio per cápita se encuentra cuarto en importancia, el 35,98\% de los hogares contrata dicho servicio. Nuevamente sólo un $0,58 \%$ de los hogares que contratan empleo doméstico se encuentran en barrios

\footnotetext{
38 Una situación que se mantiene en el tiempo en los reportes del INDEC. En particular, se reporta un $8,1 \%$ de hogares bajo la línea de pobreza en la ciudad mientras que en los partidos del GBA alcanza el 28,2\% para el primer semestre del 2019.
} 
cerrados por lo que su importancia podría ser menor a la esperada. Por otro lado, el $90,61 \%$ de ellos reside en barrios con trazado urbano (terceros en términos de ingreso), donde el $12,03 \%$ de los hogares acceden a dicho servicio. En caso de no recibir estas prestaciones, un $0,13 \%$ se encuentran en barrios cerrados, un $0,01 \%$ en zonas de quintas residenciales y un $81,9 \%$ en barrios urbanos. Esto refleja una tendencia mayor a vivir en estos lugares por parte de aquellos que adquieren el servicio de empleo doméstico.

Figura 20: Demanda de servicio doméstico por tipo de barrio

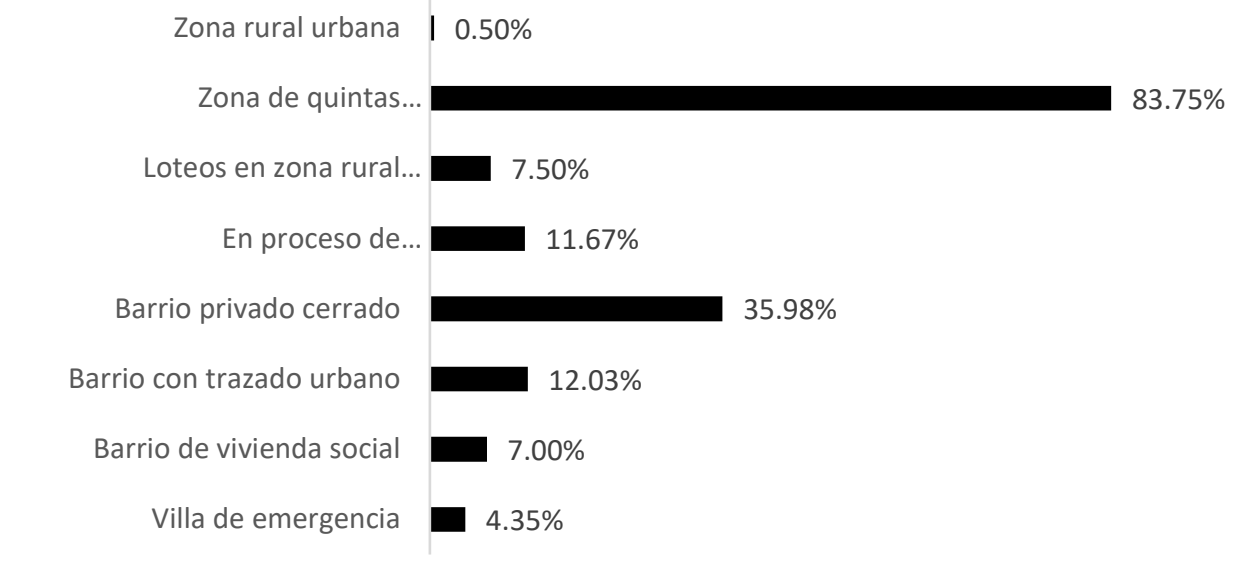

Fuente: elaboración propia en base a la Encuesta Nacional sobre la Estructura Social (ENES).

Por último, el tipo de vivienda refleja nuevamente un vínculo con el nivel de ingresos (Figura 21). Se encuentra que aquellos que viven en casa o departamento cuentan con un mayor acceso al empleo doméstico que el resto por un amplio margen. Ello toma relevancia ya que casi el $100 \%$ de los que contratan el servicio viven en casa o departamento, en caso contrario alcanzan el $96 \%$. También juega un rol importante el régimen de tenencia y la posesión de escritura. Para el primer caso puede verse que aquellos propietarios de la vivienda o cuando la misma está en sucesión acceden en mayor proporción a estas prestaciones. Esto cobra importancia dado que más del 76\% de los que contratan el servicio son propietarios de la vivienda, mientras que en caso contrario alcanzan el $65 \%$. Dentro de los propietarios, un $15,16 \%$ de los que cuentan con la escritura acceden al empleo doméstico, mientras que en caso contrario sólo un $5,14 \%$. Por otro lado, aquellos regímenes asociados a menores niveles de ingreso como ocupantes lo hacen en menor cuantía. 
Figura 21: Demanda de servicio doméstico por régimen de tenencia de la vivienda

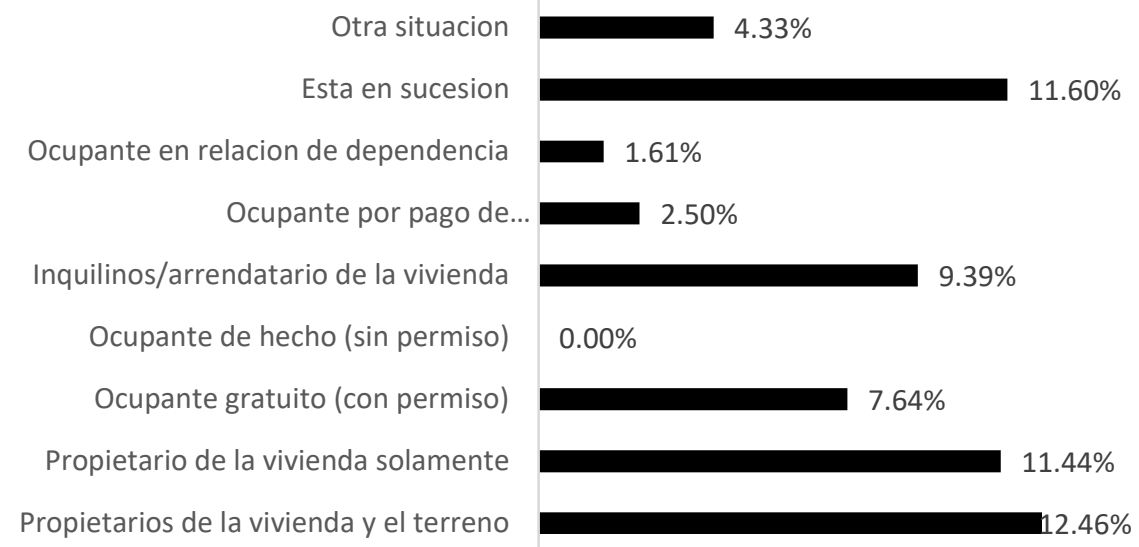

Fuente: elaboración propia en base a la Encuesta Nacional sobre la Estructura Social (ENES).

\section{V.2.3 Educación}

Al haber explicado el vínculo entre un mayor nivel de ingresos y el acceso al servicio doméstico, pareciera que también el nivel educativo de uno tendría implicancias en el mismo. Esto podría deberse al vínculo entre los años adicionales de instrucción y mayores ganancias laborales. El trabajo presentado por Galassi \& Andrada (2011) acerca de dicha relación en la Argentina, muestra tasas de retorno a la educación positivas entre el $6,6 \%$ y $10,3 \%$ para las distintas regiones del país. Es decir, un año adicional de educación incrementa el ingreso por hora del jefe de hogar entre un 6,6\% y un 10,3\% dependiendo de la ubicación geográfica. Una manera de explicar esto es que los conocimientos adquiridos permiten aumentar las competencias de las personas e incrementar así su productividad y perspectivas de ingresos (Galassi \& Andrada, 2011).

Para hablar de la relación entre educación y la demanda de empleo doméstico, se analizan las características del Principal Sostén del Hogar (PSH) (ver Figura 22). De aquellos hogares donde el mismo haya cursado y finalizado como mínimo el secundario un $14,52 \%$ contrata empleo doméstico, muy superior al caso contrario donde sólo alcanza el $7,45 \%$. Incluso, dentro de los que reciben el servicio, el $46,85 \%$ cumplen con esa condición. En el resto de los casos sólo lo logra un 29,46\%. Esto es muy importante ya que marca una diferencia notable entre los que acceden al servicio doméstico y los que no.

Si se sube la calificación mínima requerida hacia al menos haber finalizado un nivel superior al secundario/polimodal, la brecha aumenta en términos de educación y de acceso al servicio. Es decir, la diferencia porcentual de PSHs que cumplen dicho requisito entre los que contratan servicio doméstico y los que no lo hacen incrementa marcadamente con relación al caso anterior. También, se ve un mayor acceso relativo a 
dicha prestación por parte de aquellos que cumplen la condición inicial contra los que no lo hacen.

Figura 22: Demanda de servicio doméstico dado que el PSH finalizó un nivel educativo terciario o superior

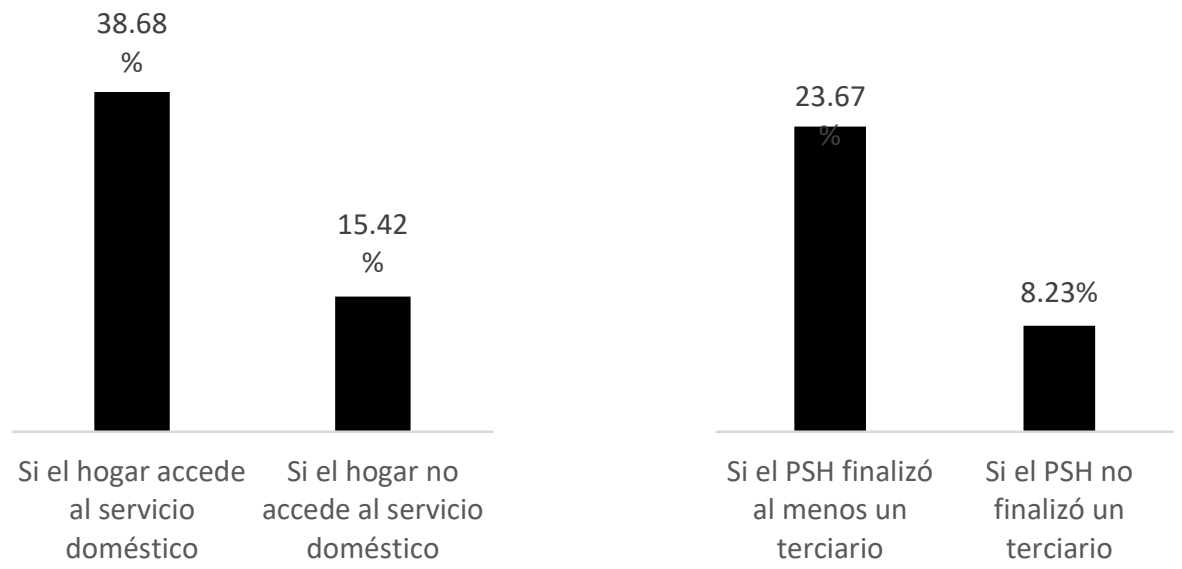

Fuente: elaboración propia en base a la Encuesta Nacional sobre la Estructura Social (ENES).

El mismo análisis puede hacerse para el caso del PSH correspondiente al hogar donde vivía el PSH encuestado a sus 15 años $^{39}$. Este enfoque arroja resultados similares donde un mayor nivel educativo por parte de ellos se vincula con un superior acceso al servicio doméstico del hogar correspondiente al PSH encuestado en el presente. A su vez, la posibilidad de contratar estas prestaciones marca un grado de instrucción mayor. Más aún, entre aquellos cuyo correspondiente PSH a los 15 años había finalizado una categoría formativa mayor al secundario/polimodal un $26,32 \%$ de los hogares recibe el servicio. En caso contrario sólo lo hacen el 10,18\% de ellos. A su vez, dentro de aquellos que emplean servicio doméstico un $20,02 \%$ de sus correspondientes PSHs a los 15 años cumplían con el requisito educativo enunciado. Entre los que no acceden al mismo, sólo un 7,36\% de sus respectivos PSHs a los 15 años habían completado un nivel de instrucción mayor al secundario/polimodal.

Por último, cabe destacar que de aquellos hogares donde el PSH tiene algún conocimiento de idioma extranjero o de computación contratan empleo doméstico un $18,91 \%$ y un $13,94 \%$ respectivamente. En caso de que el PSH no cumpla la primera o segunda condición, los porcentajes serían de un 7,7\% para el primer caso y de un 6,11\% para el segundo. Por otro lado, entre los que contratan esta prestación un $50,67 \%$ de Ios PSHs tiene conocimiento de una lengua extranjera y los que no lo reciben sólo lo tienen en un $26,86 \%$ de los casos. En cuanto al manejo de una computadora la brecha porcentual es menor entre los que acceden al servicio y los que no. Precisamente, un

\footnotetext{
${ }^{39}$ Aclaración: no se está refiriendo al PSH a sus 15 años. Sino a aquel principal proveedor del hogar donde este vivía cuando tenía 15 años. Probablemente sea un padre, una madre o cualquiera que sea el principal proveedor de ingresos al hogar.
} 
79,13\% de los primeros (refiriéndonos a los PSHs correspondientes) tiene dichos conocimientos y entre los segundos sólo un $60,38 \%$ de ellos.

\section{V.2.4 Género}

Aquí se busca ver la demanda de empleo doméstico desde una perspectiva de género donde se estudia el reparto de labores propias del hogar entre sus miembros. Es importante tener en cuenta lo encontrado por Domínguez Amorós et al. (2018) que fue comentado en el comienzo de este trabajo. Sus conclusiones derivan en una mayor carga de trabajo total para el género femenino. En promedio, el total de horas trabajadas por día es un $11 \%$ mayor para las mujeres. Lo cual se debe claramente a las tareas del hogar ya que la mujer realiza 2,57 veces la cantidad horaria dedicada por los hombres a ellas, mientras que respecto al trabajo remunerado la ratio es del 0,73.

Figura 23: Acceso al empleo doméstico por sexo del PSH

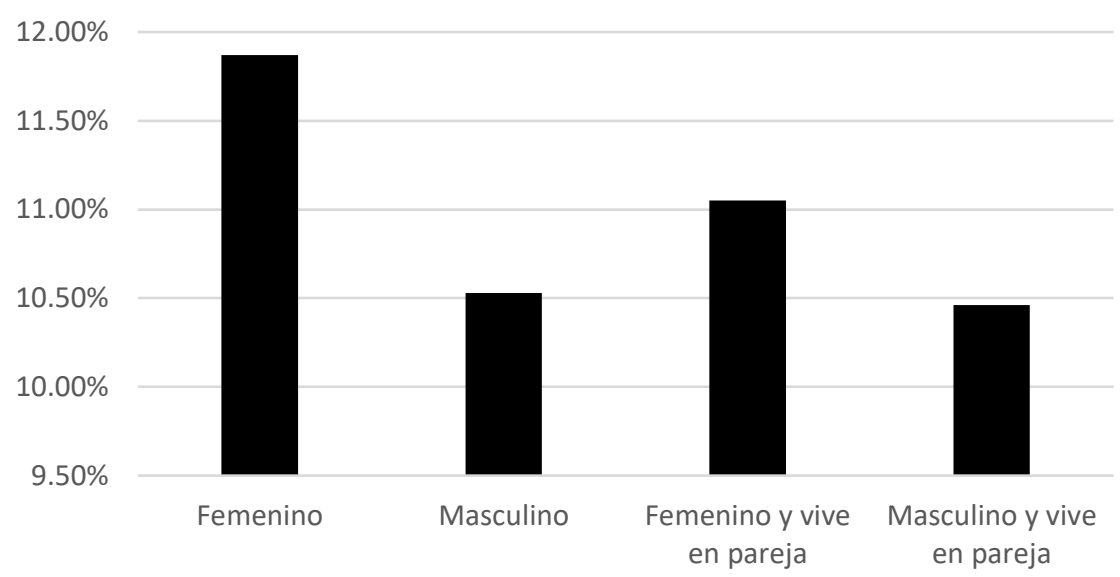

Fuente: elaboración propia en base a la Encuesta Nacional sobre la Estructura Social (ENES).

En lo que compete a este trabajo, el primer resultado es que aquellos hogares donde el PSH es mujer tienen una tendencia mayor a contratar empleadas domésticas que el resto de los casos (ver Figura 23). No existe una diferencia considerable en términos de ingreso per cápita medio entre los hogares donde el principal es de un sexo u otro, por lo que no pareciera posible explicar esta brecha con un argumento desde esa órbita. Un factor que podría explicar la diferencia en la demanda de empleo doméstico por sexo del PSH es la estructura del hogar. De hecho, al controlar por aquellos que conviven con su pareja la brecha disminuye. 
Figura 24: Composición del hogar para PSH femenino

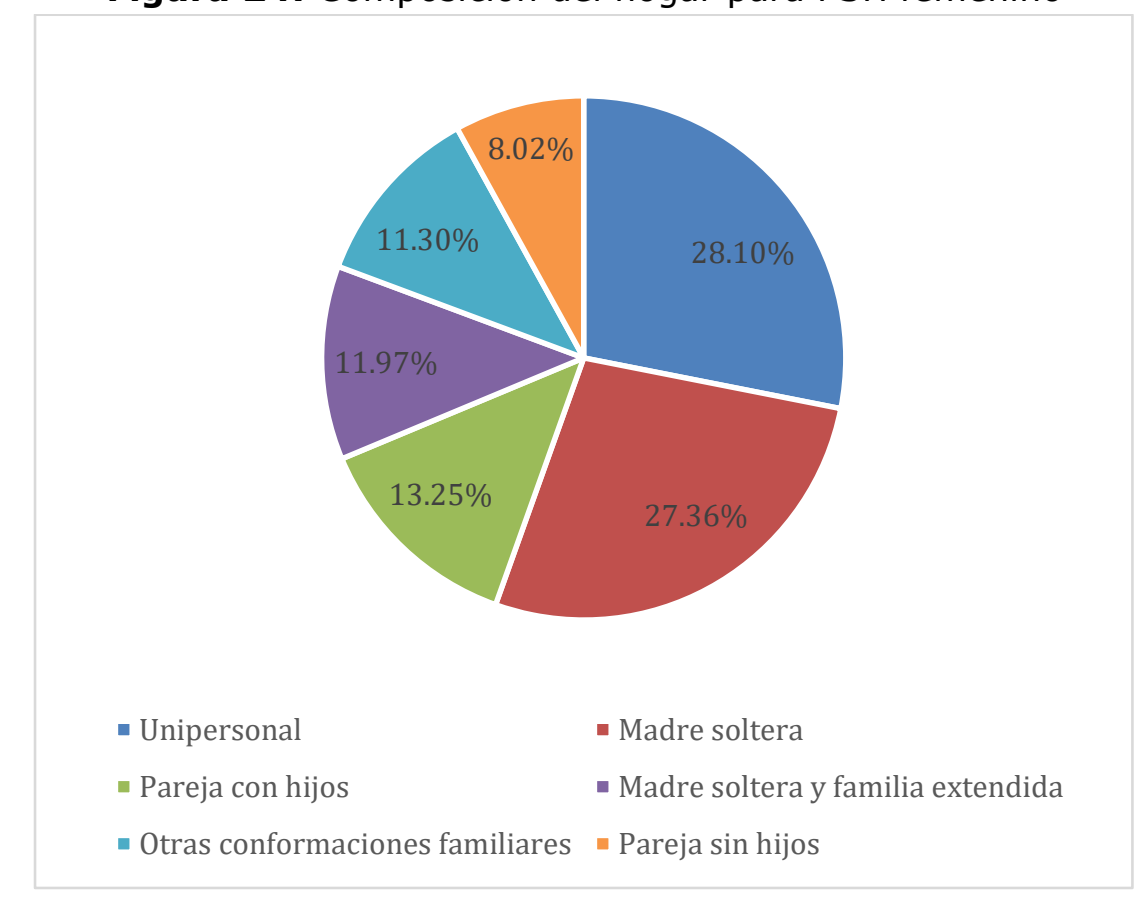

Fuente: elaboración propia en base a la Encuesta Nacional sobre la Estructura Social (ENES).

En aquellos donde el principal proveedor de ingresos es femenino se frecuentan mayormente estructuras unipersonales o monomarentales (llegan en su conjunto al $67,43 \%$ de los casos) donde la mujer no cuenta con ayuda de pareja alguna para las tareas hogareñas (Figura 24). La cantidad de casos en los que se trata de una pareja con hijos es el 13,25\% mientras que si fuera hombre sería del 52,22\% (Figura 25). Sumado a que por ser la principal proveedora probablemente tenga una mayor carga laboral y, por lo tanto, menor disponibilidad para realizar tareas no remuneradas, la mujer sufre una composición del hogar que no le abastece de ayuda para ellas en la misma proporción que si fuera hombre. Es decir, además de ser la encargada de sostener al hogar en términos monetarios también termina siendo, en la mayoría de los casos, único miembro responsable de realizar los deberes del hogar. En particular, esto último sucede con notable diferencia con relación a los casos donde el PSH es masculino. En estos, es mayor la presencia de conformaciones de "Pareja con Hijos"40 y es marcadamente menor la participación de aquellas unipersonales o de padre soltero.

\footnotetext{
${ }^{40}$ Cabe notar que en estos casos no sólo cuenta con ayuda de su pareja, sino que suele recaer en ella la mayor carga de trabajo no remunerado en el hogar.
} 
Figura 25: Composición del hogar para PSH masculino
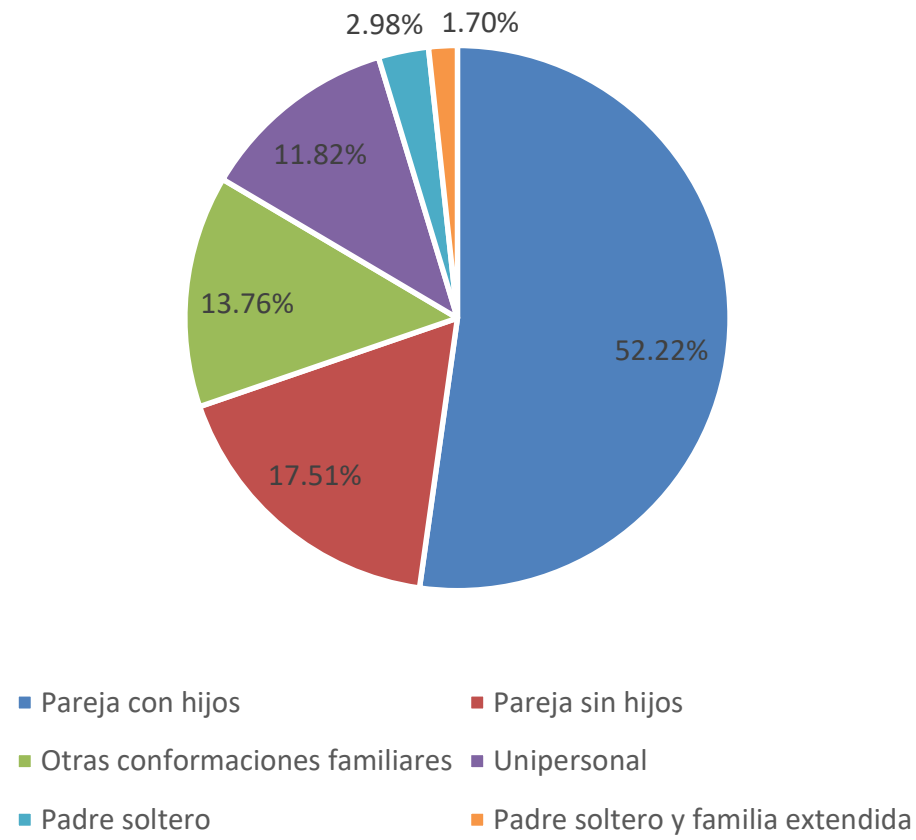

Fuente: elaboración propia en base a la Encuesta Nacional sobre la Estructura Social (ENES).

A pesar de lo expuesto acerca de la estructura familiar, se ve que la brecha disminuye al controlar por los casos donde el PSH vive en pareja, pero sigue presente. Para encontrar una explicación a esto, analizamos lo siguiente. La cantidad de horas dedicadas por semana a tareas del hogar cuando la mujer es PSH es notablemente mayor a cuando el mismo es hombre (Figura 26). Incluso la diferencia se incrementa levemente si se restringe la muestra a los casos donde el PSH vive en pareja. También se encuentra que si la mujer fuera cónyuge incrementaría su dedicación diaria en una proporción bastante mayor que en el caso de los hombres ${ }^{41}$.

Por ello, podría decirse que la brecha sigue existiendo a pesar de contar con la misma estructura familiar debido a la poca adaptación de la cantidad de trabajo en el hogar que aporta el hombre en los distintos escenarios. Es decir, al ser la mujer PSH, lo que probablemente implique una mayor dedicación temporal al trabajo remunerado, el hombre no cubre totalmente las labores que ella deja de hacer por lo que es necesario recurrir al empleo doméstico con más frecuencia.

${ }^{41}$ Pasa a ser prácticamente el doble la cantidad de horas dedicadas, con relación al conyugue hombre. 
Figura 26: Cantidad de horas semanales dedicadas a tareas del hogar por el PSH

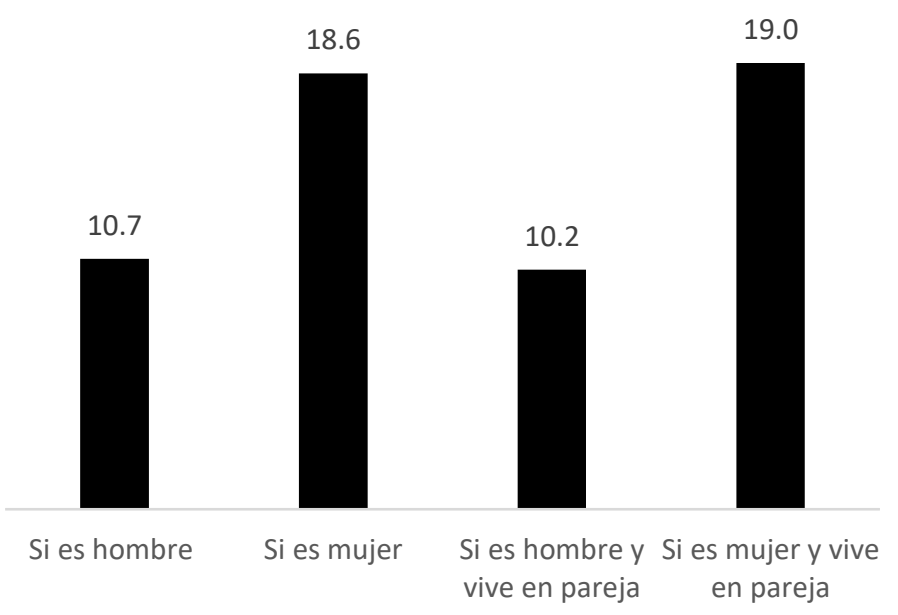

Fuente: elaboración propia en base a la Encuesta Nacional sobre la Estructura Social (ENES).

La Figura 27 trata la demanda de empleo doméstico por sexo del PSH ajustando por decil de ingreso per cápita del hogar.

Figura 27: Hogares que acceden al servicio doméstico por sexo del PSH ajustado según el decil de ingreso

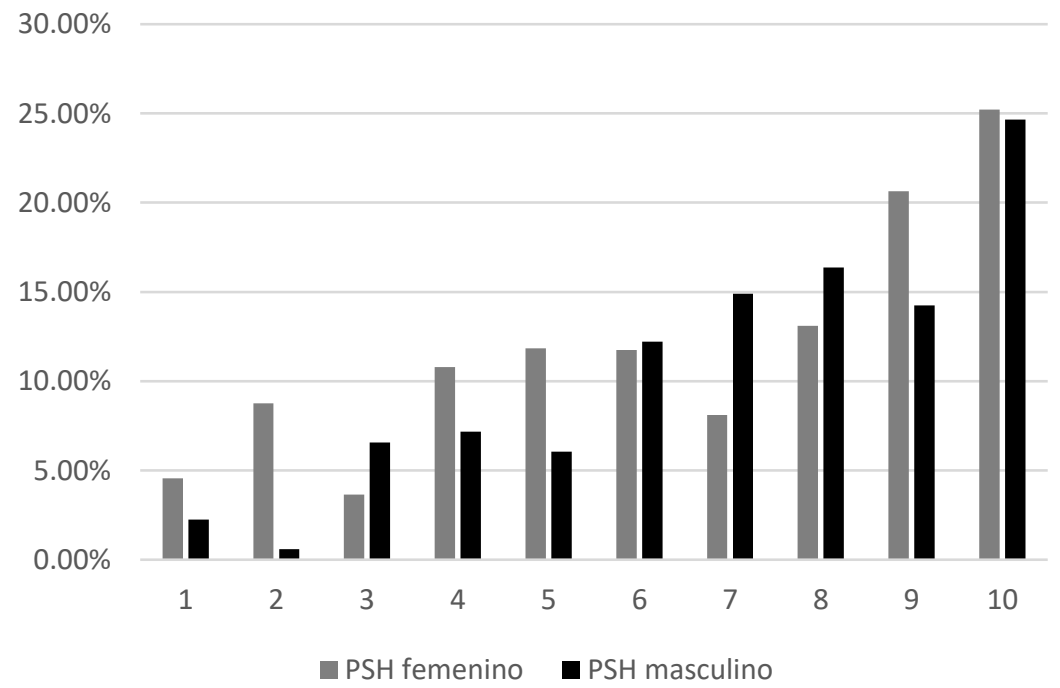

Fuente: elaboración propia en base a la Encuesta Nacional sobre la Estructura Social (ENES). 
En la Figura 27 puede verse la tendencia ya mencionada de un mayor acceso al servicio doméstico en los hogares donde el PSH es mujer. Esto último se cumple para la mayoría de los deciles y donde lo hace es con notoria diferencia. En particular se ve que la brecha es mayor en los hogares pertenecientes a los deciles más bajos de la distribución. Una explicación posible a este fenómeno es la presencia de factores culturales que contribuyen a segregar a hombres y mujeres a diversos trabajos por cuestiones de género. En particular la literatura explica que un mejor nivel educativo, un mayor acceso a empleo remunerado y pertenecer a una categoría socio-profesional calificada por parte de los hombres suelen disminuir la desigualdad en el reparto de tareas no remuneradas en el hogar. En consecuencia, las mujeres de los hogares más desfavorecidos se ven más expuestas a estas desigualdades de género en la distribución del trabajo no remunerado en el hogar (Domínguez Amorós et al. 2018). Adicionalmente, en los deciles más bajos de la distribución es donde se da una mayor participación de hogares donde el principal proveedor de ingresos es femenino, lo que constituye otra causa posible de la brecha.

\section{Implicancias en términos de políticas públicas}

Por la cantidad de puestos de trabajo que produce y por la progresiva necesidad de estos servicios dado el envejecimiento poblacional y el crecimiento en la participación laboral de las mujeres, es muy importante que se realicen reformas que permitan combatir las dificultades que presenta este rubro para sus trabajadores y empleadores. En este camino, es central el papel de la educación para permitir a los trabajadores poder alcanzar mejores oportunidades, teniendo así también mayor poder de negociación y capacidad para reclamar sus derechos laborales.

Tal como la OIT (2015) el camino hacia una formalización de la economía permite al Estado aumentar su recaudación, mejorar las condiciones laborales e incrementa el alcance de la política económica. De esta manera, el primer paso para mejorar el bienestar de las empleadas domésticas y sus empleadores es realizar políticas públicas que disminuyan la informalidad de este sector.

En este sentido, los avances que subyacen de la Ley 26.844 sancionada en el 2013 son fundamentales. Los mismos permiten incluir dentro del alcance de las regulaciones laborales nacionales a las empleadas domésticas brindándoles beneficios y derechos que previamente no ostentaban. Este tipo de medidas, en torno a extender el alcance de las normativas laborales incorporando este rubro de trabajadores como tales, constituyen el primer paso hacia su formalización (OIT, 2016).

El trabajo de Roncolato \& Kucera (2008) muestra que la evidencia empírica de los efectos de nuevas regulaciones sobre la informalidad es diferente a lo que la escuela neoclásica esperaría. En particular, algunos estudios encuentran una relación positiva entre incrementar las normativas y la porción de trabajo formal. A su vez, la mayoría muestran una relación nula entre ambos. Con estos resultados, los autores concluyen que lo 
importante no es elegir entre regular o no hacerlo sino encontrar el marco regulatorio óptimo que maximice el bienestar de los implicados.

Sin embargo, hay muchos determinantes que afectan la formalización o no de los trabajadores más allá de la normativa en que estén encuadrados. Dentro de estos se encuentran, el conocimiento por parte de ellos y de los empleadores de las nuevas regulaciones, la confianza que tengan en las instituciones del Estado (Birgin, 2009), cómo se hacen cumplir las leyes y los costos que conlleva la adherencia al régimen, entre otros aspectos.

Concretamente, la realización de campañas de concientización acerca de las obligaciones que uno tiene como empleador y los derechos que debería reclamar siendo empleado doméstico resultan clave en el camino hacia la formalidad. Es muy importante que uno como empleador sepa que la Ley 26.063 (sancionada en el 2005) permite deducir del Impuesto a las Ganancias tanto el sueldo como las contribuciones patronales a la seguridad social que se originen en la contratación de empleados domésticos ${ }^{42}$. De la misma manera, también es esencial que un empleado doméstico sepa que le corresponden días de licencia paga por enfermedad o que el organismo de resolución de conflictos en la Ciudad de Buenos Aires (Tribunal de Trabajo para el Personal de Casas Particulares) es totalmente gratuito para las actuaciones administrativas. Por estas razones, que la sociedad tome conciencia de la necesidad de acoger a estos trabajadores dentro del mercado laboral formal, de los costos efectivos de contratarlos dentro del marco legal y que los empleados sepan qué cosas pueden reclamar, es una parte más que importante dentro de las políticas que pueda hacer el Estado con relación al objetivo nombrado previamente.

Por otro lado, controlar que se cumpla la ley también es un factor para tener en cuenta, ya que sin un mecanismo que permita hacer cumplir las normativas, éstas carecen de sustento. En este mercado, la realización de inspecciones laborales se dificulta al ser un sector laboral disperso geográficamente e implicar la entrada al hogar de muchas personas, lo cual puede no ser permitido por el marco legal vigente. Aún más dificultades pueden presentarse por la falta de conocimiento explicada anteriormente, ausencia de tiempo o dinero, la falta de confianza en las autoridades o no querer efectuar reclamos por miedo a perder el trabajo, entre otros.

A pesar de ello, hubo mecanismos que valen la pena tener en cuenta para ser aplicados en nuestro país. Como hizo España en 2011, podría contribuir permitir un lapso en el cual se pudiera registrar formalmente a sus empleadas domésticas sin posibilidad de sanciones ni reclamos por previos incumplimientos ("blanqueo"). De esta manera, podría permitirse este período de "gracia" explicando que luego los controles y sanciones serían más estrictos. También es de utilidad utilizar un esquema de entrevistas al empleador y empleado similar a lo aplicado en Sudáfrica e Irlanda (OIT, 2016), en lugares neutrales

\footnotetext{
${ }^{42}$ Se aplica un máximo a deducir igual a la Ganancia Mínima No Imponible. La misma fue de pesos 85.848,99 para el 2019.
} 
en caso de conflicto ${ }^{43}$.

Por último, otro factor relevante hacia la formalización consiste en facilitar y bajar los costos de esta para ambas partes del vínculo laboral. Sería interesante considerar el efecto de extender las deducciones impositivas que ya existen o encontrar alguna manera de disminuir el costo de despido. Una estrategia novedosa sería implementar un

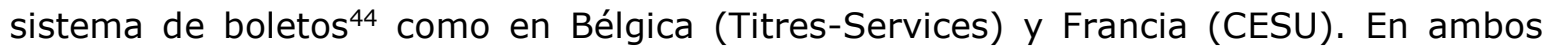
países se buscó la formalización del sector fomentando la creación de empresas proveedoras del servicio doméstico. En particular, en el caso belga se otorgó exclusividad a dichas empresas no permitiendo las relaciones laborales directas entre consumidor y empleado. Esto permitió aumentar el empleo formal del sector, así como también un mayor acceso a estos servicios de aquellos más necesitados como pueden ser las personas mayores, hogares con un solo padre/madre o personas con discapacidad.

Un aspecto muy importante es que la deducción impositiva a las personas (físicas o jurídicas) que compren estos boletos se realizara automáticamente a través del sistema, sin necesidad de pasos posteriores. A su vez, en Francia existe la posibilidad de que empresas accedan a boletos especiales que entregan a sus empleados como parte de su compensación y ellas pueden usarlo para deducciones impositivas. Un esquema de este tipo más allá de los incentivos financieros lleva a una relación triangular de trabajo fomentada por las empresas proveedoras del servicio que a su vez libera a los particulares de las típicas obligaciones de un empleador (OIT, 2016) ${ }^{45}$. Incluso permitiría disminuir el pago de asistencias sociales, aumentar la recaudación de la seguridad social, la creación de empleo (tanto de empleadas domésticas como de puestos gerenciales y administrativos en las empresas, entre otros) y aumento del consumo en consecuencia. En términos de recaudación impositiva, el efecto neto es incierto y depende de la relación entre creación de empleo (con su impacto en el consumo) y los incentivos financieros que se otorguen.

Para que el sistema funcione es importante que el precio efectivo pagado luego de la deducción impositiva sea cercano al que rige en el mercado informal. En países como Austria, los beneficios otorgados por el Estado determinaron una brecha considerable por lo que no se fomentó significativamente la creación de nuevos puestos de trabajo formales (OIT, 2016).

Medidas como las propuestas permitieron en Bélgica y Francia aumentar la formalidad del sector, la creación de empleo y el acceso a estos servicios de personas que antes no habían podido ${ }^{46}$. A su vez, lograron una mayor capacitación de los empleados. Por otro

\footnotetext{
${ }^{43}$ En particular en Sudáfrica el resultado fue exitoso, se obtuvieron compromisos escritos para regularizar su situación de aquellos empleadores que no cumplían con las normativas. El resultado fue que un $90 \%$ de ellos habían regularizado por completo la situación laboral de sus empleados domésticos al cabo de un año. Para más información recurrir al texto Formalizing Domestic Work (OIT, 2016).

${ }^{44}$ Aquel que quiera acceder al servicio doméstico debe comprar boletos que le dan el derecho a recibir una determinada cantidad de horas de este.

${ }^{45}$ Esto probablemente permita disminuir los costos de contratación por parte de los particulares o suavizarlos en el tiempo.

${ }^{46}$ En Dinamarca, el 75\% de los usuarios del sistema de deducción impositiva para mayores de 65 años no había accedido a estos servicios previamente. Con un sistema similar, Suecia logró una mejora en la formalidad del rubro.
} 
lado, existen estudios que vinculan este tipo de políticas con una reducción en las horas trabajadas de los empleados domésticos. Sin embargo, sus resultados no son concluyentes.

Con reformas de este estilo se busca fomentar el traslado de relaciones de trabajo hacia el mercado formal y la creación de nuevos empleos formales. Al formalizar al sector, uno permite incorporar a los beneficios y derechos que brinda el marco legal a las empleadas domésticas. Además, si se logra calificar la labor de las empleadas de manera que puedan mejorar su productividad esto podría mejorar sus ingresos y el servicio otorgado. También, sería de interés beneficiar a aquellos hogares necesitados de estas prestaciones pero que al costo actual no pueden. Todo esto, podría derivar en un mayor bienestar para la sociedad, mejorando la situación actual de los que intervienen en este mercado. Por supuesto, hay que ser precavidos en no precarizar las condiciones laborales en busca de disminuir la informalidad.

Finalmente, al "blanquear" este mercado de trabajo, se facilita la recolección de datos acerca del mismo y sus integrantes. Esto permitiría un mejor análisis de las medidas tomadas y el diseño de políticas que aborden estas problemáticas de una manera más eficaz.

\section{Consideraciones finales}

El envejecimiento poblacional y el proceso de inserción femenina al mundo laboral ponen al empleo doméstico en un rol de progresiva relevancia en la estructura económica. Las necesidades de estos servicios van a incrementar considerablemente y por eso es crucial solucionar los obstáculos que se presentan en este mercado, en particular los relacionados a la informalidad y precariedad laboral. Muchos países, en particular aquellos en etapas más avanzadas de rotación en la pirámide demográfica, han realizado numerosas reformas con el objetivo de mejorar el bienestar de todos los intervinientes en este mercado. En Argentina, se destaca la Ley sancionada en el 2013 que rige estos contratos laborales. Sin embargo, falta mucho por hacer en ese camino.

Para realizar políticas públicas eficaces con dicho objetivo, se requiere un conocimiento integral de los factores que caracterizan el funcionamiento de este mercado. A pesar de ello, la mayoría de los trabajos presentes en la literatura se limitan al estudio de ciertos aspectos concernientes a los oferentes de empleo doméstico. Con el objetivo de proveer herramientas a quienes realicen política económica, este trabajo busca brindar un análisis completo de los determinantes tanto de la oferta como de la demanda de estos servicios.

Los resultados al analizar la oferta de empleo doméstico muestran que se trata de un sector altamente informal, condicionado por la falta de educación de sus trabajadores que les restringe el acceso a trabajos en mejores condiciones y su capacidad para reclamar los derechos laborales que les corresponde. El análisis sugiere que el salario mínimo podría estar siendo un punto de referencia a la hora de pactar contratos tanto 
en el mercado formal como en el informal. Adicionalmente, las remuneraciones en el último se caracterizan por una mayor volatilidad.

A partir de la EPH se puede observar la fuerte presencia femenina que representa casi la totalidad de los puestos de trabajo. En concordancia con la literatura, se encontró una presencia marcadamente mayor de los inmigrantes en el empleo doméstico que en el resto de la economía. Lo expresado en este párrafo deja en evidencia la necesidad de entender que las políticas dirigidas a este sector deben tener en consideración los aspectos migratorios y de género.

Finalmente, la evidencia muestra que se trata de un rubro con bajo nivel de ingresos lo que se relaciona a su vez con uno de los menores niveles de productividad en la economía. Esto podría llevar a un fuerte vínculo con la pobreza, lo que es respaldado por los datos al mostrar que los hogares donde el jefe es empleado doméstico tienen una incidencia de la pobreza mucho mayor a la media nacional. A su vez, se encontró que políticas sectoriales que busquen aumentar el nivel de ingresos (ya sea por transferencias directas o que lleven a aumentar el salario por hora) de los trabajadores de este rubro mejoran notablemente el bienestar de ellos y sus familias. Además, podría ser una herramienta útil dentro de un plan integral que busque reducir la pobreza en todo el país.

Al analizar la demanda de empleo doméstico los resultados fueron en concordancia con lo que uno podría esperar. Se encuentra una estrecha relación entre el nivel de ingresos de un hogar y el acceso a estas prestaciones. Probablemente la conclusión más interesante de esta sección sea el vínculo igual o más estrecho entre la autopercepción del nivel de ingresos o posición social y la contratación de empleadas domésticas. Luego, el análisis geográfico encontró que probablemente existan factores diferentes al nivel de ingreso medio en una región que puedan contrarrestar sus efectos en la demanda de estos servicios. Si bien pudo verse que el poder adquisitivo juega un papel central, también lo hacen la oferta de mano de obra no calificada, la desigualdad, la pobreza y el desempleo. También se encontró, como podía esperarse dada su alta correlación con el nivel de ingresos, un mayor nivel educativo en aquellos que acceden al empleo doméstico. Esto mismo muestra una relación más estrecha si se tiene en consideración la educación de aquellos a cargo del actual PSH cuando este era un adolescente.

Desde la perspectiva de género se evidencia que aquellos hogares donde la mujer es la que mayores ingresos lleva al hogar tienden a contratar más empleadas domésticas que el resto. Esto coincide con la literatura que muestra una desigual distribución en las tareas del hogar en las parejas de doble ingreso donde la mujer resulta perjudicada. Esto último se encuentra con mayor fortaleza en los deciles más bajos de la distribución, lo que puede ser explicado por mayores desigualdades respecto al rol de la mujer en el hogar. Sumado a ello, cuando la mujer es la principal proveedora de ingresos se suelen frecuentar estructuras unipersonales o monoparentales donde la misma debe ocuparse de las tareas hogareñas prácticamente por si sola. A diferencia de esto, si el PSH fuera hombre dichas composiciones del hogar disminuyen marcadamente.

Con este trabajo se busca facilitar el diseño de políticas públicas que busquen un mayor 
bienestar en la sociedad. Los resultados sugieren que se necesitan medidas para mejorar la situación de los trabajadores del empleo doméstico. Para ello, es crucial entender el papel que juega la perspectiva de género en ambas partes de este mercado y la inmigración del lado de la oferta. Asimismo, la formalización y la educación debieran ser parte de los pilares de futuras reformas. En particular, extender el alcance de la ley a estas relaciones laborales es necesario en el camino hacia una menor informalidad, pero se requieren otras medidas para lograrlo. Las mismas podrían resumirse en facilitar el acceso a la justicia, desincentivar la informalidad e incentivar la realización de contratos de trabajo formales. En este sentido, las reformas realizadas en otros países como en Bélgica, Francia o Sudáfrica (OIT, 2016) debieran ser utilizadas para estudiar su aplicabilidad en nuestro país. Cabe notar que en varias de ellas se alcanzaron otros objetivos como la generación de empleo, capacitación de las empleadas domésticas y un mayor acceso a estas prestaciones por parte de aquellos que más las necesitan.

Se espera que este análisis permita poner en agenda la necesidad de realizar reformas en este mercado y sirva de motivación para futuros trabajos de investigación sobre el tema. 


\section{Referencias}

Anderson, B. (2001). Just another job? Paying for domestic work. Gender and Development, 9(1), 23-33.

Batthyany, K. (2012). Estudio sobre trabajo doméstico en Uruguay. Organización Internacional del Trabajo (OIT).

Berniell, I., Berniell, L., de la Mata, D., \& Marchionni, M. (2019). Gender gaps in labor informality: The motherhood effect. Documento de Trabajo No. 247. CEDLAS.

Bertranou, F., \& Casanova, L. (2013). Informalidad laboral en Argentina: segmentos críticos y políticas para la formalización. Organización Internacional del Trabajo (OIT).

Birgin, H. (2009). Sin acceso a la justicia: el caso de las trabajadoras domésticas en Argentina. En Valenzuela, M. E., \& Mora, C. Trabajo doméstico: un largo camino hacia el trabajo decente (págs. 261-285). Organización Internacional del Trabajo (OIT).

Blundell, R., Pistaferri, L., \& Saporta-Eksten, I. (2016). Consumption inequality and family labor supply. American Economic Review, 106(2), 387-435.

Ceriani, P., Courtis, C., Pacecca, M. I., Asa, P., \& Pautassi, L. (2009). Migración y trabajo doméstico en Argentina: las precariedades en el marco global. En Valenzuela, M. E., \& Mora, C. Trabajo doméstico: un largo camino hacia el trabajo decente (pp. 147-191). Organización Internacional del Trabajo (OIT).

Dinkelman, T., \& Ranchhod, V. (2010). Evidence on the impact of minimum wage laws in an informal sector: Domestic workers in South Africa. Southern Africa Labour and Development Research Unit.

Domínguez Amorós, M., Muñis, L., \& Rubilar Donoso, G. (2018). El trabajo doméstico y de cuidados en las parejas de doble ingreso. Análisis comparativo entre España, Argentina y Chile. Papers. Revista de Sociología, 104(2), 337-374.

Galassi, G. L., \& Andrada, M. J. (2011). Relación entre educación e ingresos en las regiones geográficas de Argentina. Papeles de población, 17(69), 257-290.

Groisman, F. (2012). Salario mínimo y empleo en Argentina. Revista de Economía Política de Buenos Aires, 6(11), 9-47.

Groisman, F., \& Suárez, A. L. (2010). Segregación residencial e inserción laboral en el Conurbano Bonaerense. Población de Buenos Aires, 7(11), 7-28.

Heffetz, O., \& Frank, R. (2011). Preferences for status: Evidence and economic implications. En Benhabib, J., Bisin, A., \& Jackson, M. O. (Eds.). Handbook of social economics (Vol. 1A, pp. 69-91). Elsevier.

INDEC (2016). Incidencia de la pobreza y de la indigencia en 31 aglomerados urbanos. Resultados segundo trimestre de 2016. Informes técnicos. Dirección Encuesta Permanente de Hogares, INDEC. https://www.indec.gob.ar/uploads/informesdeprensa/eph_pobreza_01_16.pdf

Khamis, M. (2008). Does the minimum wage have a higher impact on the informal than 
on the formal labor market? Evidence from quasi-experiments. IZA Discussion Paper No. 3911. Institute for the Study of Labor.

Maurizio, R. (2007). Migraciones internacionales en Argentina: un análisis de sus determinantes y de su relación con el mercado de trabajo. Nuevos Documentos Cedes No. 30. CEDES.

Ministerio de Trabajo y Seguridad Social (2015). Trabajo doméstico e impacto de las políticas públicas en Uruguay. República Oriental del Uruguay.

Ministerio de Trabajo y Seguridad Social (2019). Trabajo Doméstico Remunerado en Uruguay. República Oriental del Uruguay.

OIT (2010). Domestic workers in Thailand: their situation, challenges and the way forward. International Labour Organization.

OIT (2013). Domestic workers across the world: Global and regional statistics and the extent of legal protection. International Labour Organization.

OIT (2015). Global estimates on migrant workers. International Labour Organization. https://www.ilo.org/wcmsp5/groups/public/---dgreports/--dcomm/documents/publication/wcms_436343.pdf

OIT (2015). Recomendación sobre la transición de la economía informal a la economía formal. Conferencia General de la Organización Internacional del Trabajo.

OIT (2016). Formalizing domestic work. International Labour Organization.

OIT (2016). Políticas de formalización del trabajo doméstico en América Latina y el Caribe. Organización Internacional del Trabajo.

Órdenes Carvajal, C. (2016). Servicio doméstico en Chile: caracterización, evolución y determinantes de su partición laboral [Tesis de maestría]. Universidad de Chile.

Roncolato, L., \& Kucera, D. (2008). Informal employment: Two contested policy issues. International Labour Review, 147(4), 321-348.

Schteingart, D. (2017). La estructura productiva: La madre de todas las batallas contra la pobreza. Sociedad, Núm. 37, 43-75.

Stancanelli, E. G., \& Stratton, L. S. (2014). Maids, appliances and couples' housework: The demand for inputs to domestic production. Economica, 81(323), 445-467.

Van Biesebroeck, J. (2015). How tight is the link between wages and productivity? A survey of the literature. Conditions of Work and Employment Series No. 54. International Labour Organization.

Velásquez Pinto, M. D. (2017). Salario mínimo y empleo: evidencia empírica y relevancia para América Latina. Serie Condiciones de Trabajo y Empleo No. 93. Organización Internacional del Trabajo. 


\section{Anexo}

Figura A1: Variación de los puestos de trabajo respecto a la tasa de informalidad en el empleo doméstico

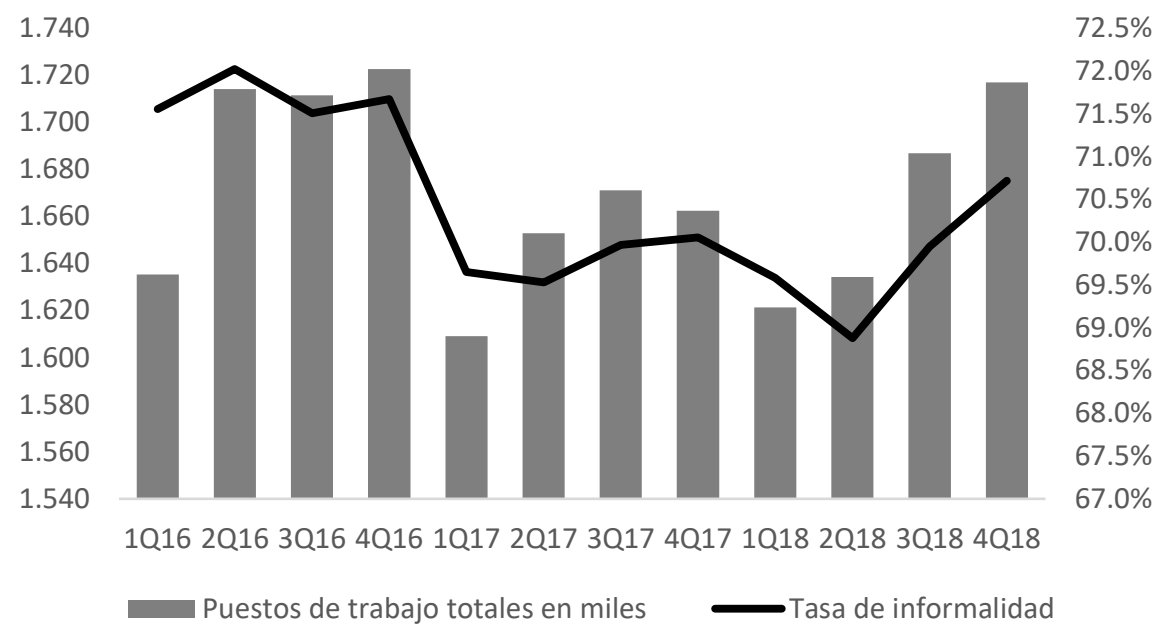

Fuente: elaboración propia a partir de la Cuenta de Generación del Ingreso e Insumo de Mano de Obra del INDEC.

Figura A2: Ingreso per cápita por regiones ${ }^{47}$

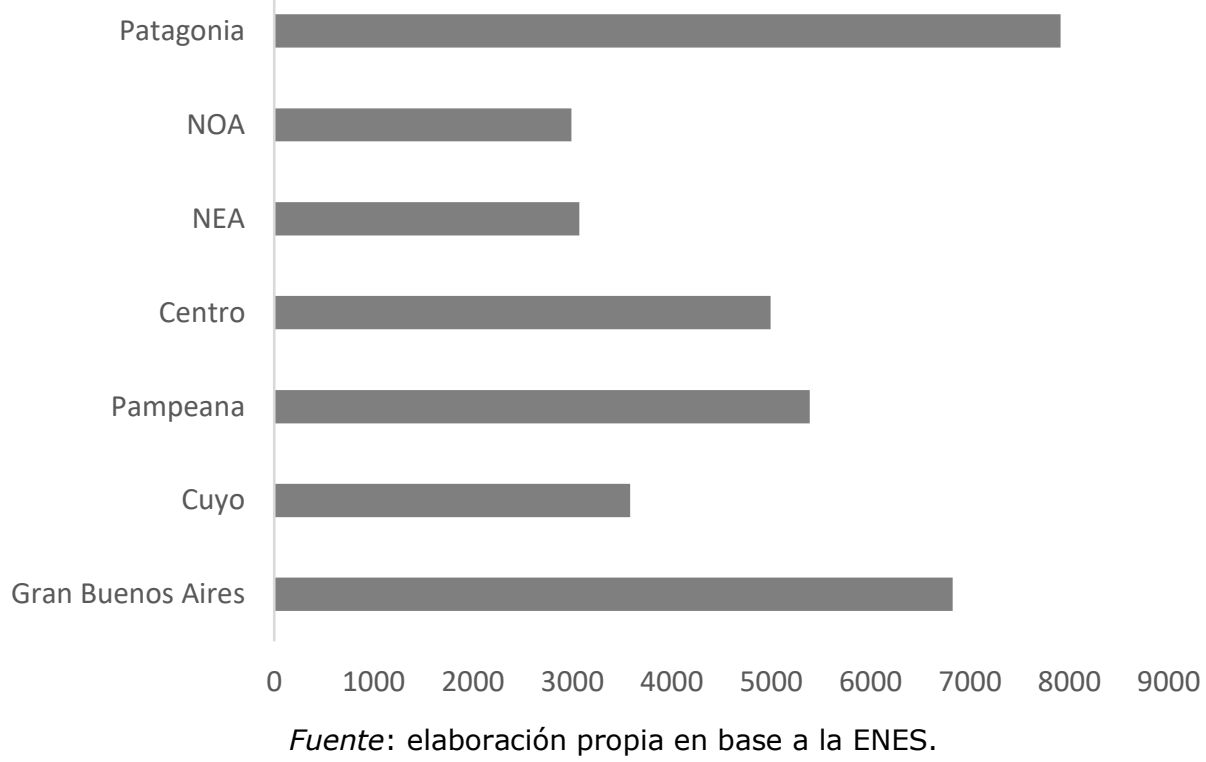

47 El ingreso per cápita del Gran Buenos Aires puede desagregarse entre CABA y los 24 partidos bonaerenses que releva la encuesta. El correspondiente a CABA supera al de la Patagonia. El nivel del resto del Gran Buenos aires sigue siendo superior al resto de las regiones (excluyendo CABA y Patagonia). 
Tabla A1: Incidencia de la pobreza ante ajustes en los ingresos de los empleados domésticos

Tasas correspondientes al primer semestre del 2019

\begin{tabular}{lcccc} 
& \multicolumn{2}{c}{ Total aglomerados urbanos } & $\begin{array}{c}\text { Dado que el jefe de hogar es } \\
\text { empleado doméstico }\end{array}$ \\
\cline { 2 - 5 } & $\begin{array}{c}\text { Incidencia de la } \\
\text { pobreza en } \\
\text { hogares }\end{array}$ & $\begin{array}{c}\text { Incidencia de la } \\
\text { pobreza en } \\
\text { personas }\end{array}$ & $\begin{array}{c}\text { Incidencia de la } \\
\text { pobreza en } \\
\text { hogares }\end{array}$ & $\begin{array}{c}\text { Incidencia de } \\
\text { la pobreza en } \\
\text { personas }\end{array}$ \\
\hline $\begin{array}{l}\text { Sin modificaciones } \\
\begin{array}{l}\text { Incremento de un 5\% al } \\
\text { ingreso por hora de los }\end{array}\end{array}$ & $25.38 \%$ & $35.37 \%$ & $48.31 \%$ & $56.57 \%$ \\
$\begin{array}{l}\text { empleados domésticos } \\
\text { Incremento de un 10\% al }\end{array}$ & $25.30 \%$ & $35.28 \%$ & $47.63 \%$ & $55.91 \%$ \\
$\begin{array}{l}\text { ingreso por hora de los } \\
\text { empleados domésticos }\end{array}$ & $25.19 \%$ & $35.17 \%$ & $46.04 \%$ & $54.64 \%$ \\
$\begin{array}{l}\text { Incremento de un 20\% al } \\
\text { ingreso por hora de los } \\
\text { empleados domésticos }\end{array}$ & $25.06 \%$ & $35.02 \%$ & $44.47 \%$ & $53.28 \%$ \\
$\begin{array}{l}\text { Incremento de un } 50 \% \text { al } \\
\text { ingreso por hora de los }\end{array}$ & $24.74 \%$ & $34.61 \%$ & $39.91 \%$ & $48.38 \%$ \\
empleados domésticos & & & & \\
$\begin{array}{l}\text { Transferencia de } 1000 \text { pesos a } \\
\text { cada empleado doméstico }\end{array}$ & $25.11 \%$ & $35.09 \%$ & $45.01 \%$ & $53.91 \%$ \\
$\begin{array}{l}\text { Transferencia de } 2000 \text { pesos a } \\
\text { cada empleado doméstico }\end{array}$ & $24.87 \%$ & $34.83 \%$ & $42.06 \%$ & $51.69 \%$ \\
$\begin{array}{l}\text { Transferencia de } 3000 \text { pesos a } \\
\text { cada empleado doméstico }\end{array}$ & $24.67 \%$ & $34.59 \%$ & $40.09 \%$ & $50.07 \%$ \\
$\begin{array}{l}\text { Transferencia de } 4000 \text { pesos a } \\
\text { cada empleado doméstico }\end{array}$ & $24.52 \%$ & $34.41 \%$ & $38.19 \%$ & $48.20 \%$ \\
$\begin{array}{l}\text { Transferencia de } 5000 \text { pesos a } \\
\text { cada empleado doméstico }\end{array}$ & $24.26 \%$ & $34.08 \%$ & $35.22 \%$ & $45.01 \%$ \\
\hline \hline
\end{tabular}

Fuente: elaboración propia en base a la EPH y mediciones de la Canasta Básica Total del INDEC. 